\title{
What drives inter-organisational knowledge management? The cause and effect analysis using a multi-layer multi-criteria decision-making framework
}

\begin{abstract}
Purpose. Knowledge management seeks collaborative practices among organisations to generate technical, adapt, and share knowledge to obtain a sustainable competitive advantage in cross-border business activities. This paper is set to disentangle the crucial determinants of knowledge management in inter-organisational arrangements settings.

Method. In the first stage, after an in-depth literature review, the main knowledge management drivers are identified. In the second stage, based on the identified drivers, the importance and relationship between the drivers are evaluated by expert's opinions from academic and executive activists. Eventually, in the last stage, a multi-layer decision-making approach has been proposed and employed to determine the relationship and the importance of the drivers.

Findings. The findings of this paper assess the ranking of the different elements from experts' opinions and discuss important theoretical and managerial implications. The influential factors were identified through an extensive literature review, which combined with the views of experts from academia and industry (international firms). Furthermore, the ranking of factors based on the experts' overall opinion was used to discuss theoretical and managerial contributions.

Originality. This research provides a better understanding of the interrelationships between the key drivers of knowledge management, which helps management draw more effective strategies to address the cultural differences between firms. Moreover, understanding of the importance of the systems and structures that define the nature of the collaboration in inter-organisational settings, as well as the risks related to those are presented in this research.
\end{abstract}

Keywords: Knowledge management, inter-organisational arrangements, grey decision-making trial and evaluation laboratory (G-DEMATEL), DEMATEL-based Analytic Network Process (DANP) 


\section{Introduction}

The primary business challenge of the twenty-first century is the transition from an industrial to a knowledge economy. Knowledge management is a critical component of such a transition's success (Lachance et al., 2019; Anjaria, 2020). In an industrial setting, effective knowledge management enables organizations to collect, share, and utilize knowledge systematically across internal departments and between parties. (Oliva, 2014) asserts that knowledge management requires businesses to invest time and money, the organization's two most valuable resources. The value placed on knowledge sharing between parties has increased, and managers now view knowledge sharing with their customers as a source of creativity. The phenomenon enables managers to make more informed decisions that contribute to long-term sustainability. Despite the industrial sector's emphasis on knowledge management, due to the emergence of collaborative academia projects between multiple universities and the link between universities and industry, initiatives should consider both parties' perspectives on knowledge gaps across organizations.

Contrary to popular belief, while knowledge management is gaining traction in organizations of all sizes and sectors worldwide, the discipline has not yet achieved the organizational stature that other business functions and operations have (Vaccaro et al., 2010). Several scientists assert that organizational maturity and size are impediments to achieving knowledge management in organizations (Oliva and Kotabe, 2019), while others assert that insufficient budget allocation and traditional organizational chart structure are the primary reasons for firms' failure to achieve a functional knowledge management infrastructure (Mazorodze and Buckley, 2019). Additionally, one of the primary reasons for such dysfunctionality is a dearth of knowledge management strategies aligned with the organization's overall performance (Hayter and Link, 2020). For example, a recent study discovered that supply chain members might suffer from a lack of integration and knowledge, which has a detrimental effect on overall performance and budget control in an industrial organization (Pérez-Salazar et al., 2017). When it comes to more advanced projects involving university faculty, they have a unique perspective on the barriers and primary drivers of enabling inter-organizational knowledge sharing in organizations (Martn-de Castro, 2015). Thus, the primary issue that has not been addressed in the literature is the ambiguity and limited understanding of the critical factors that contribute to successful knowledge management, as well as the fact that these factors should not be viewed in isolation. In other words, despite 
understanding the key drivers of inter-organizational knowledge management, there is a lack of clarity regarding how businesses of varying sizes and types should leverage this phenomenon.

The difficulties inherent in implementing and implementing effective knowledge management strategies and operations are not unique to organizational settings. When it comes to collaborations between businesses, the ability to generate knowledge collaboratively and share it with partners becomes critical to maintaining a sustainable competitive edge in international business activities. Despite their importance in inter-organizational arrangements, research has generally concentrated on high-level drivers of effective knowledge management, such as knowledge elicitation and knowledge transfer, and has done so primarily in the context of specific organizations and communities. A small number of scholars have sought to identify and comprehend the unique drivers of successful knowledge management in inter-organizational collaborations, mainly when such collaborations involve international business engagement (Cricelli and Grimaldi, 2010). Additionally, several recent studies, such as (Karamat et al., 2019), have defined the barriers and drivers to knowledge management implementation in organizations. However, this research takes a broader view of this definition by examining it from two perspectives. The authors believe that, due to widespread collaboration in multinational corporations, business owners and academic members should contribute their perspectives on the most cutting-edge knowledge management enablers. This void in the literature on inter-organizational knowledge management impairs firms' ability to generate technical knowledge, adapt it innovatively, and share it with partners engaged in a cooperative, frequently international business activities to sustain a competitive advantage (Ho et al., 2018).

The following research contributes to (Crupi et al., 2020; Zhou and Nunes, 2016), where the authors successfully shed light on the critical nature of knowledge sharing in organizations, demonstrating how it increases productivity and encourages innovation. However, we are examining the degree to which each inter-organizational knowledge management driver adapts from two perspectives. The authors' primary objective is to demonstrate that both academic members and industry owners must agree on a hierarchy of drivers and that there should not be a single solution for every business. As a result, firms should determine which prioritization strategy is most appropriate for their organizations based on their business theme. 
This article describes a research project designed to address this gap in the literature. Our findings are informed by the perspectives of industry and academic experts, who were analyzed using grey system analysis - a novel approach not previously used in this context that takes into account the context's dynamic and subjective nature. To accomplish this goal, a series of knowledge management drivers in inter-organizational arrangements were identified and combined with practitioner perspectives. After categorizing the factors and their interdependences, DEMATEL was used to visualize the intricate relationship between these elements using diagrams. A matrix of influence is created and used to visualize the cause-and-effect relationships between the various factors. These relationships are then used to derive several conclusions and implications for knowledge management theory and practice, most notably in the context of interorganizational arrangements.

The remainder of this essay is structured as follows: A review of the literature on knowledge management in inter-organizational arrangements is presented, outlining the theoretical foundations for key knowledge management factors, most notably those related to knowledge sharing, seeking, and transfer. The methodology section describes the procedures used to collect and analyze data from industry and academic experts. The combination of G-DEMATEL and the Analytical Network Process (ANP) is described in detail to assess the ranking of various elements based on expert opinion and then visualize the results. A case study is used to describe knowledge management in inter-organizational arrangements. Finally, theoretical and managerial contributions are discussed, followed by the research conclusions.

\section{Literature review}

\section{Inter-organisational knowledge management}

The inter-organisational arrangement is an intricate concept that has been studied from different perspectives (Agostini et al., 2020; Easterby-Smith et al., 2008; Rezaei et al., 2020). The seminal work in the field refers back to Grant (1996) who argues that firms can gain a competitive advantage by developing knowledge and learning capabilities. In a similar vein, Lane and Lubatkin (1998) build on the wealth of inter-organisational learning and focused on the capability of firms to explore, value and exploit the novel knowledge obtained from external sources. That is, interorganisational arrangements involve the contribution of a minimum of two firms, which calls for 
a better understanding of the dynamics undertaking among such organisations (Easterby-Smith et al., 2008). When it comes to cross-border activities such as international joint ventures, foreign firms must obtain knowledge from local partners (Kale \& Anand, 2006).

A considerable amount of research has explored the concept from the perspectives of legitimacy, control, and coordination (Alimadadi et al., 2019). In this regard, Björkman et al. (2007) highlight that inter-organisational arrangements can take advantage of the knowledge of collaborative organisations to generate a novel knowledge combination, which contributes to knowledge acquisition in firms. Therefore, inter-organisational knowledge management seeks collaboration among firms to create technical knowledge, apply innovative adaptation, and share it among partners to obtain a sustainable competitive advantage in international business activities (Chen et al., 2016; Xie et al., 2018). In this vein, knowledge systems are crucial elements that enable organisations to transfer knowledge throughout the firm. These systems and structures (such as IT systems) allude to tools for effective knowledge management processes (Thannhuber et al., 2017).

As a complex phenomenon, inter-organisational knowledge management includes two significant pillars. First, knowledge transfer is considered an important pillar of knowledge management (Nooshinfard \& Nemati-Anaraki, 2014). Transfer capability refers to the state of difficulty in making changes in routine processes. If a new process is easily put in the working routine, it has a high transfer capability since employers had the least trouble adapting to such information. When it comes to inter-organisational settings, knowledge transfer refers to a process in which different organisational units apply, exchange and/or are influenced by other organisational actors' knowledge and experience (Fang et al., 2013). In this vein, it creates a longrun relationship that exchanges tangible resources among at least two organisations (Alimadadi et al., 2019). In the process of internationalisation of firms, inter-organisational knowledge transfer is particularly important for value creation and competitive advantage development (Del Giudice et al., 2017; Sukumar et al., 2020). In this regard, in the context of international entrepreneurship, born-globals are highly dependent on the knowledge of the targeted local markets, regulations as well as the information about the potential stakeholders such as suppliers, consumers, etc. (Cavusgil \& Knight, 2015). Second, international knowledge acquisition deals with the process in which local partners acquire a source of information from a foreign party through the process of 
offshoring (Jensen, 2009). In this vein, inter-organisational knowledge transfer plays an important role since it faces different barriers such as institutional distance during the process (Jafari Sadeghi et al., 2019; Wang et al., 2019). Nevertheless, building on the wealth material of knowledge transfer and acquisition, it is worth disentangling other key factors of inter-organisational knowledge management.

\section{The underpinning drivers}

Several dynamic capabilities underpin inter-organisational knowledge management. Following Easterby-Smith et al. (2008), we argue that the knowledge transfer cycle is decomposed of a donor, a recipient, and the knowledge flow. The main attempt of the following research is to identify the core factors influencing both sides of the information sharing procedure. A key factor influencing both sides is the organisational culture and leadership perspective for knowledge sharing. Easterby-Smith and Lyles (2011) believe that past experiences and organisational culture affect both donor and recipient. Research shows that this factor has a more substantial effect rather than motivation in transferring knowledge (Minbaeva et al., 2014; Yi Ying et al., 2012). The positive social tie between employers is a decisive element in learning both in the receiver and sending side of the cycle (Song, 2015).

When it comes to inter-organisational settings, socio-cultural variations rise the necessity of applying different knowledge management practices (Pauluzzo \& Cagnina, 2019). It should be noted that the availability of knowledge does not guarantee that employees will spend time and effort using it. Rather, the strength of ties shared norms, and trust is the central concepts of organisational socio-cultural relationships that contribute to the level of trust and collaboration between organisations (Raza et al., 2018). That is, knowledge availability is imperative for international knowledge management since it determines whether it is worth developing knowledge inside the firm or absorbing it from the external collaborative partner (Loon, 2019). The availability of knowledge can also be dependent on the complexity of innovation since R\&D practices and innovative actions can ensure successful knowledge creation within the firm.

The intricate business environment and technology advancement led innovative organisations to build inter-organisational collaboration to adopt recent technologies and generate new knowledge essential for their businesses (Chen et al., 2007; Wang \& Meng, 2019). In this vein, 
complexity is deemed as a crucial element that can make knowledge tacit (Balland et al., 2019). Knowledge complexity impacts the process of knowledge transfer and integration within the organisation (Mat \& Razak, 2011). As such, higher knowledge complexity lead to more challenges for organisations in their process of knowledge integration (Kim \& Anand, 2018). Furthermore, poor knowledge integration jeopardises the firm's innovative actions as a result of administration and time pressures as well as information security issues (Maleki \& Rosiello, 2019). On the other hand, the complexity of knowledge makes it hard to understand and the high intensity of this complexity deters firms from fast and innovative knowledge learning (Jafari Sadeghi et al., 2014; Ruoslahti, 2020). In an inter-organisational setting, therefore, technology advancement such as simplified IT-based knowledge databases assist in higher integration and knowledge accessibility (Garousi Mokhtarzadeh et al., 2020).

The literature review shows that companies tend to resolve the complexity of the forthcoming knowledge in their industry. When the receiver finds an expected knowledge complex, the chance of learning deteriorated (Flöthmann et al., 2018). The convoluted data takes more energy and becomes a barrier to acquiring knowledge at a proper pace (Díaz-Reza et al., 2020). Therefore, designing simplified structures has been a concern in recent years, along with other data transformations in organisations. The state of collaboration and how employers should be appropriately managed is found to be a common investigated issue among authors in the past few years (Akram et al., 2020; Nugroho, 2018; Oyemomi et al., 2019). The knowledge receiver perceives the risk of new information. In inter-organisational knowledge management (especially through strategic alliances), organisations need to assess the possible pitfalls (risks) and merits of new knowledge since a wrong choice conduce the budget and time loss (Canzaniello et al., 2017; Subramanian et al., 2018). In this regard, institutional factors such as cultural and social differences impact international knowledge management (Jafari-Sadeghi et al., 2020).

On the other hand, a supply chain case study shows that vague information has severe adverse effects on a firm's overall performance (Ponis \& Koronis, 2013; Marra, Ho, \& Edwards, 2012). Indeed, it is confirmed that organisational learning relies on the acquired prior knowledge and its characteristics, which can affect the knowledge management outcome. In this vein, knowledge ambiguity intervenes as a major challenge for knowledge management practices, particularly, for knowledge learning and transfer (Ho et al., 2019). Literature defines knowledge ambiguity as to 
the level of difficulty and clarity for understanding the causal impacts of partner organisation's knowledge as well as the application of obtained such knowledge (Liao \& Hu, 2007). In this regard, the ambiguity highlights whether the proposed knowledge from the donor is clear to understand since the donor may omit the main ideas to save its competitive advantage. In interorganisational knowledge management practices such as cross-country knowledge acquisition, knowledge ambiguity is an imperative factor that depends on institutional distance, cultural rationality, various knowledge management systems, and diverse goals of alliance partners (Bhatti et al., 2020; Ho et al., 2018). Therefore, it is deemed that there is a significant relationship between knowledge ambiguity inter-organisational knowledge management (Ho et al., 2019).

However, the evaluation of risk and trust in terms of the contract has been probed by the authors (Cheng et al., 2013). A precise amount of security is always needed for the long-term relationship and further services from the donor. That is, the trust contracts are signed between parties to assure high-quality knowledge transfer (Olaisen \& Revang, 2017; Ouakouak \& Ouedraogo, 2019; Rungsithong \& Meyer, 2020). Furthermore, literature in the field of international business stressed the role of trust within and between organisational arrangements (Chen et al., 2007; Yang \& Maxwell, 2011). According to, trust is defined as "the confidence between two parties with the understanding that no party will exploit the other's vulnerability" (Koohang et al., 2017). In interorganisational relationships, prior research asserts that trust is created when a firm has confidence in the integrity and reliability of the partner (Sankowska \& Paliszkiewicz, 2016). In this vein, firms are relying on the perfection of knowledge to assist them in boosting knowledge. Thus, they need to make sure that knowledge is functional in their firm over time. On the other hand, actuation is particularly important since it represents the motivation of recipients to learn the coming knowledge in the organisation (Curado \& Vieira, 2019). It affects behavioural perspectives of employees including knowledge management and creativity behaviour (Wang \& Hou, 2015). As such, actuation has a two-way relationship since it defines how well the information is thought and learned, respectively.

On the other hand, absorptive aptitude (capability) helps organisations to improve their innovative actions and performance by using updated knowledge (Kostopoulos et al., 2011). In the extant literature, absorptive aptitude has been defined differently. For instance, for Cohen and Levinthal (1990), absorptive aptitude is the "ability of a firm to recognise the value of new 
information, assimilate it and apply to commercial ends". Observed as the technology advancement receptivity, Zahra and George (2002) formulate it as the organisation's capability to acquire, absorb, transform and apply knowledge. Absorptive aptitude is also deemed as the firm's ability to learn from others (Duodu \& Rowlinson, 2019). Hence, it is perceived as the firm's internal process, which shows how they can prior knowledge such as experience and existing practices (Easterby-Smith et al., 2008). However, this learning process depends on similarities among organisations in terms of organisational structures, dominant logic and knowledge bases and is influenced by its past experiences, culture, and knowledge retention capabilities (Chen et al., 2016; Cohen \& Levinthal, 1990). Similarly, in an inter-organisational setting, absorptive aptitude is key knowledge management that refers to absorbing external knowledge from partner organisations (Easterby-Smith et al., 2008).

The review of the literature reveals that businesses frequently resolve the complexity of forthcoming knowledge in their industry. When a receiver encounters an expected knowledge complex, the receiver's probability of learning decreases (Flöthmann et al., 2018). Complex data consumes more energy and acts as a barrier to knowledge acquisition at the appropriate pace (DazReza et al., 2020). As a result, the design of simplified structures and other data transformations within organizations has been a focus in recent years. The state of collaboration and how employers should be managed appropriately has emerged as a frequently researched topic among authors over the last few years (Akram et al., 2020; Nugroho, 2018; Oyemomi et al., 2019). The knowledge recipient assesses the risk associated with new information. However, the authors examined the evaluation of risk and trust in the context of the contract (Cheng et al., 2013). A precise amount of security is always required to ensure the donor's long-term relationship and future services. As a result, parties enter into trust contracts to ensure high-quality knowledge transfer (Olaisen and Revang, 2017; Ouakouak and Ouedraogo, 2019; Rungsithong and Meyer, 2020).

\section{Methodology}

Three significant steps have been designed to evaluate the key indicators that drive knowledge management processes (sharing, seeking, and transferring) in inter-organizational arrangements: identification, data collection, and analysis. In the first stage, after an in-depth literature review, the leading knowledge management drivers are identified. In the second stage, based on the identified drivers, the importance and relationship between the drivers are evaluated by expert's 
opinions from academic and executive activists. Eventually, a multi-layer decision-making approach has been proposed and employed in the last stage to determine the drivers' relationship and importance. In Figure 1, the considered framework is illustrated, and each stage and step are presented in detail.

Please insert Figure 1 here.

\section{Stage 1. Identification}

According to the findings in the literature review section, a search procedure was conducted to achieve the critical knowledge management factors. At the first stage, popular keywords "knowledge management," "information sharing," "knowledge sharing," and "inter-organisational knowledge sharing" were searched in the Google Scholar search engine. The aim was to find the most relevant research published in the period between 2010 and 2020. In the initial search, about 300 results were obtained. Several knowledge management drivers were introduced and implemented in the 1990s, but due to their limited importance in the recent literature, they were omitted in this research. The scholars moved towards the next phase using accessible scientific databases Elsevier, Emerald, and Springer for the best outcomes. The findings were finally crosschecked with the WOS database to ensure the reliability of selecting data.

As mentioned earlier in the literature review section, the knowledge transfer cycle is decomposed of a donor, a recipient, and the knowledge flow. The main attempt of the following research is to identify the core factors influencing both sides of the information sharing procedure. In Figure 2, the final 67 articles are distributed using a mixed chart according to their correspondent criteria. The column graph depicts the annual paper count, while the lines depict the driver distribution over the same period.

Please insert Figure 2 here.

Knowledge drivers such as ambiguity or risk have been given less attention in recent years. On the other hand, companies' obligation to manage RandD budgets and construct efficient IT-based 
infrastructures has been pushed towards properly managing information databases. Therefore, knowledge availability and systems structures have been given more considerable attention lately. Conspicuously, the inter-dependencies between collaboration and cultural habits among employees have always been a controversial issue. Trust has also been an essential component in transferring knowledge since knowledge adapters are reluctant to absorb new information at the first stage. The chart also depicts that the ease of knowledge transfer and information availability through innovation is becoming a trend.

Figure $3 a$ and Figure $3 b$ demonstrate the dispensation of 67 relevant papers based on the author and knowledge sharing drivers. The distinctive form of the criterion is expected to cause the "culture and social ties" and "absorptive aptitude" as the most influential factors after the evaluation of factors using the hybrid COCOSO-G-DEMATEL approach.

Please insert Figure $3_{\mathrm{a}}$ here.

Please insert Figure $3_{\mathrm{b}}$ here.

\section{Stage 2. Data gathering}

The previous stage identified the critical drivers of knowledge management processes (sharing, seeking, and transfer) in inter-organizational arrangements based on relevant literature. The expert opinion was consulted to investigate the relationship between these drivers and quantify their significance in inter-organizational arrangements. Two groups of experts from academia and business are chosen in this regard. To begin, the authors held several online sessions lasting approximately four hours each with academic experts with expertise in knowledge management, knowledge sharing, seeking and transfer, and inter-organizational arrangements. Each of these groups consisted of four individuals, and they were asked to score the questionnaire in a single form based on their overall attitudes during the session. To ensure concise results, each group was composed of two men and two women. Because academic members could have provided more insight based on their teaching experience and industry presence, two members had more than 
eight years of teaching experience, while the other two had a greater presence in the industry regardless of their academic experience.

To better understand the critical inter-organizational knowledge management drivers, we considered business executives who have implemented knowledge management in their organizations. This research was conducted with a group of executive managers from companies in Italy and the United Kingdom. Due to the importance and diversity of businesses, Table 1 contains information about the business managers.

\section{Please insert Table 1 here.}

For data gathering, based on the information required for DEMATEL, CoCoSo, and DANP methods, a questionnaire has been designed and dispersed among the academic and business experts. Academic experts (A) are coded as $\mathrm{A}_{1}$ to $\mathrm{A}_{4}$, and business experts (B) are coded from $\mathrm{B}_{1}$ to $\mathrm{B}_{5}$. First of all, a brief definition of each knowledge management driver has been presented to the experts as follows.

- Absorptive aptitude $\left(\mathbf{D}_{1}\right)$ is considered the ability to understand the value of new knowledge and utilise it properly. This factor is influenced by its past experiences, culture, and knowledge retention capabilities.

- Transfer capability $\left(\mathbf{D}_{2}\right)$ is the state of difficulty in making changes in routine processes. If a new process is easily put in the working routine, it has a high transfer capability since employers had the least trouble adapting to such information.

- Actuation $\left(\mathbf{D}_{3}\right)$ shows the motivation of recipients to learn the coming knowledge in the organisation. This factor has a two-way relationship since it defines how well the information is thought and learned.

- Ambiguity $\left(\mathbf{D}_{4}\right)$ is the proposed knowledge from the donor clear to understand? The vague knowledge has severe drawbacks in the organisation's overall performance in the long term. Sometimes the donor may omit main ideas to save its competitive advantage.

- Complexity $\left(\mathbf{D}_{5}\right)$ the complexity of knowledge makes it hard to understand. The high number of this factor is time-consuming and deters firms from learning knowledge fast and 
innovate. Therefore, the recipients prefer simplified IT-based knowledge databases rather than complicated handbooks.

- Trust $\left(\mathbf{D}_{6}\right)$ firms rely on the perfection of the knowledge to assist them in boosting knowledge. Thus, they need to make sure that knowledge is functional in their firm over time.

- System and structures $\left(\mathbf{D}_{7}\right)$ this newly emerged term defines the knowledge systems that enable organisations to transfer knowledge through their firm. Researches aim to identify the most crucial factors affecting these structures to formulate a functional framework.

- Culture and social ties $\left(\mathbf{D}_{\mathbf{8}}\right)$ the availability of knowledge does not guarantee that employees will spend time and effort using it. Tie strength shared norms, and trust is the central concept of organisational social relationships. The high value of this factor illustrates that employers are more collaborative and trust each other for KM. Organisational hierarchy and high bureaucracy are the core barriers to reach a proper knowledge-sharing environment

- Risk ( $\mathbf{D}_{9}$ ) Due to the importance of the strategic alliance with the coming knowledge, organisations need to assess the merits and possible pitfalls of new knowledge since a wrong choice conduce the budget and time loss

- Knowledge availability $\left(\mathbf{D}_{10}\right)$ is it worth developing knowledge inside the firm or absorbing it from outside? This factor assesses the functionality of open innovation and RandD benefits. Making the right decision boosts the product development process and saves money in an economic crisis.

After explaining the knowledge management drivers and research objectives to the experts, each expert evaluates how each factor affects other factors (direct effect) and how it is affected by other factors (reverse effect). In this regard, a seven pull-down linguistic terms scale including strongly effective, effective, nearly effective, neither effective nor ineffective, nearly ineffective, ineffective, strongly ineffective has been designed. These linguistic variables are transferred to grey values as Table 2 .

Please insert Table 2 here. 
The questionnaire considered in this study is a squared matrix $(10 \times 10)$ with an empty main diagonal. Each expert should respond to 90 comparisons for knowledge management drivers extracted.

\section{Stage 3. Data analysis}

Following data collection and validation by expert opinion via a questionnaire, a multi-layer decision-making approach was developed for evaluating the key drivers of knowledge management in inter-organizational arrangements. There are numerous ways to incorporate uncertainty into decision-making procedures, including the use of grey values, fuzzy sets, and stochastic values (Mahdiraji et al., 2019). Additionally, some recent approaches, such as hesitant or intuitionistic, are designed to incorporate uncertainty into decision-making (Mahmoudi et al., 2019). Grey values and numbers are considered in this research when evaluating and quantifying knowledge management drivers. As a result, the Grey DEMATEL, DANP (a combination of the Decision-Making Trial and Evaluation Laboratory (DEMATEL) method and the Analytical Network Process (ANP) method), and CoCoSo (combined compromise solution) methods are used, as explained below.

\section{CoCoSo}

This method is a newly proposed and reliable algorithm to evaluate alternatives based on different criteria. The method was initially introduced in 2019 (Yazdani et al., 2019) and was developed for uncertain versions, including Pythagorean Fuzzy (Peng et al., 2019) and fuzzy CoCoSo (Ecer and Pamucar, 2020). In this research, the CoCoSo method has been employed to compare the results of knowledge management drivers based on different types of businesses and industries. By applying this method, knowledge management drivers assessed different industries based on their executive manager's opinions. The five-step CoCoSo method is presented as follows (Yazdani et al., 2019).

(1) Design the initial decision-making matrix as follows. Note that $x_{i j}$ is the assessment is the $\mathrm{i}^{\text {th }}$ alternative based on $\mathrm{j}^{\text {th }}$ criteria.

$$
x_{i j}=\left[\begin{array}{ccc}
x_{11} & \cdots & x_{1 n} \\
\vdots & \ddots & \vdots \\
x_{m 1} & \cdots & x_{m n}
\end{array}\right]
$$


$\mathrm{i}=1,2, \ldots, \mathrm{m} ; \mathrm{j}=1,2, \ldots, \mathrm{n}$

(2) Based on the benefit and cost criterion, by using the two following formulas, the initial decision-making matrix is normalised. Note that $r_{i j}$ is the normalised value of the $i^{\text {th }}$ alternative based on $\mathrm{j}^{\text {th }}$ criteria.

$$
\begin{aligned}
& \text { Benefit } \rightarrow r_{i j}=\frac{x_{i j}-\min \left(x_{i j}\right)}{\max \left(x_{i j}\right)-\min \left(x_{i j}\right)} \\
& \text { Cost } \rightarrow r_{i j}=\frac{\max \left(x_{i j}\right)-x_{i j}}{\max \left(x_{i j}\right)-\min \left(x_{i j}\right)}
\end{aligned}
$$

(3) The total of the weighted comparability sequence (S) and the whole of the power weight of comparability sequences $(\mathrm{P})$ for each alternative is calculated by the two following formulas.

$$
\begin{aligned}
& S_{i}=\sum_{j=1}^{n}\left(w_{j} \cdot r_{i j}\right) \\
& P_{i}=\sum_{j=1}^{n}\left(r_{i j}\right)^{w_{j}}
\end{aligned}
$$

(4) The arithmetic mean of sums of $\mathrm{P}_{i}$ and $\mathrm{S}_{i}$ scores $\left(\mathrm{k}_{\mathrm{ia}}\right)$, the sum of relative scores of $\mathrm{P}_{i}$ and $\mathrm{S}_{\mathrm{i}}$ compared to the best $\left(\mathrm{k}_{\mathrm{ib}}\right)$, and the balanced compromise of $\mathrm{P}_{\mathrm{i}}$ and $\mathrm{S}_{\mathrm{i}}$ scores $\left(\mathrm{k}_{\mathrm{ic}}\right)$ are all calculated by following formulas. In equation 8 , Lambda is determined by the decisionmaker and is usually near 0.5 .

$$
\begin{aligned}
k_{i a} & =\frac{P_{i}+S_{i}}{\sum_{i=1}^{m}\left(P_{i}+S_{i}\right)} \\
k_{i b} & =\frac{S_{i}}{\operatorname{Min}\left(S_{i}\right)}+\frac{P_{i}}{\operatorname{Min}\left(P_{i}\right)} \\
k_{i c} & =\frac{\lambda P_{i}+(1-\lambda) \cdot S_{i}}{\left[\lambda \cdot \operatorname{Max}\left(S_{i}\right)\right]+\left[(1-\lambda) \cdot \operatorname{Max}\left(P_{i}\right)\right]}
\end{aligned}
$$

(5) The final evaluation and ranking of alternatives $\left(\mathrm{k}_{\mathrm{i}}\right)$ are emanated from the following formula. 


$$
k_{i}=\left(k_{i a} \cdot k_{i b} \cdot k_{i c}\right)^{\frac{1}{3}}+\left(\frac{1}{3}\left[k_{i a}+k_{i b}+k_{i c}\right]\right)
$$

\section{G-DEMATEL}

Living in an unpredictable world with the least assurance of information validity requires a solution for decision-making under this circumstance. In the $1980 \mathrm{~s}$, the grey system was introduced to scholars by (Deng J, 1989) to provide a framework for overcoming vague data decision-making problems. Since then, the approach has been highly used in different areas of science, such as agriculture, economics, medicine, or management. In the rest of this section, a brief explanation of the main notations and operations of grey systems are proposed, and by the introduction of CFCS, a brief demonstration of DEMATEL is given.

Every grey number has an upper and lower bound. The bound shows the range of uncertainty in providing information from experts. The grey number $(\otimes X)$ is shown as $\otimes X=[\underline{x}, \bar{x}]$ where $(\bar{x})$ is the high range and $(\underline{x})$ is the lower range of the grey number, respectively. The following equations show the behaviour of grey numbers for basic mathematical operations.

$$
\begin{aligned}
& \otimes X_{1}+\otimes X_{2}=\left[\underline{x_{1}}+\underline{x_{2}}, \overline{x_{1}}+\overline{x_{2}}\right] \\
& \otimes X_{1}-\otimes X_{2}=\left[\underline{x_{1}}-\underline{x_{2}}, \overline{x_{1}}-\overline{x_{2}}\right] \\
& \otimes X_{1} \times \otimes X_{2} \\
& =\left[\min \left(\underline{x_{1}} \cdot \underline{x_{2}}, \underline{x_{2}} \cdot \overline{x_{1}}, \underline{x_{1}} \cdot \overline{x_{2}}, \overline{x_{1}} \cdot \overline{x_{2}}\right), \max \left(\underline{x_{1}} \cdot \underline{x_{2}}, \underline{x_{2}} \cdot \overline{x_{1}}, \underline{x_{1}} \cdot \overline{x_{2}}, \overline{x_{1}} \cdot \overline{x_{2}}\right)\right] \\
& \otimes X_{1} \div \otimes X_{2}=\left[\underline{x_{1}} \cdot \overline{x_{1}}\right] \times\left[\frac{1}{x_{2}}, \frac{1}{\overline{x_{2}}}\right]
\end{aligned}
$$

An efficient problem-solving solution in the grey environment is to use the grey aggregation methodologies. In this procedure, the grey problem is converted to crisp scores. The three-step Converting Fuzzy Data into Crisp Scores (CFCS) methodology is among the most populated approaches to reach crisp values (Wu and Lee, 2007). The three steps are illustrated below:

(1) Normalisation 


$$
\begin{aligned}
& \underline{\otimes} \tilde{x}_{i j}^{p}=\left[\underline{\otimes} x_{i j}^{p}-\min _{j} \underline{\otimes} x_{i j}^{p}\right] / \triangle_{\min }^{\max } \\
& \bar{\otimes} \tilde{x}_{i j}^{p}=\left[\bar{\otimes} x_{i j}^{p}-\min _{j} \bar{\otimes} x_{i j}^{p}\right] / \triangle_{\min }^{\max }
\end{aligned}
$$

Where

$$
\triangle_{\min }^{\max }=\min _{j} \bar{\otimes} x_{i j}^{p}-\min _{j} x_{i j}^{p}
$$

(2) Determining the total normalised crisp value

$$
Y_{i j}^{p}=\frac{\left(\underline{\otimes} x_{i j}^{p}\left(1-\underline{\otimes} x_{i j}^{p}\right)+\left(\bar{\otimes} x_{i j}^{p} \times \bar{\otimes} x_{i j}^{p}\right)\right)}{1-\underline{\otimes} x_{i j}^{p}+\bar{\otimes} x_{i j}^{p}}
$$

(3) Crisp number results are as follows

$$
Z_{i j}^{p}=\min _{j} \otimes x_{i j}^{p}+Y_{i j}^{p} \cdot \triangle_{\min }^{\max }
$$

Since five business volunteers have filled the questionnaires, the average $Z_{i j}^{p}$ is calculated and transferred to the DEMATEL matrix. The merit of the DEMATEL approach is its capability to visualise the intricate relationship between metrics using diagrams. This method was first used by (Gabus and Fontela, 1973) to plot the strength of the relationship between different components and has been widely used in different areas of science. In this methodology, it is presumed that several elements exist. These measures are put in a pairwise direct relation matrix for evaluation. In the next step, the influence matrix is constructed through the normalised direct-relation matrix. Following the total relation matrix formulation, a cause/effect relationship emerges between components. In other words, the G-DEMATEL approach is translated as below (Fu, Zhu, and Sarkis, 2012):

(1) According to the proposed Table 2, linguistic variables are transferred to grey values, and the influence comparison scale for criterion is defined.

(2) The grey pairwise influence relationship $n \times n$ matrix is formulated and using the CFCS method, the grey values are transformed into crisp components. Since there are five evaluators, the average $Z_{i j}$ matrix is constructed as below: 


$$
Z_{i j}=\frac{1}{p}\left(Z_{i j}^{1}+Z_{i j}^{2}+\cdots+Z_{i j}^{p}\right)
$$

(3) The normalised direct-relation matrix is formulated using the following equations:

$$
\begin{aligned}
& s=\frac{1}{\max _{1 \leq i \leq n} \sum_{j}^{n} Z_{i j}} \quad ; \forall i j=1,2, \ldots, n \\
& N=s \times N
\end{aligned}
$$

(4) Construction of the total relation matrix

$$
T=N+N^{2}+N^{2}+\cdots=\sum_{i=1}^{\infty} N^{i}=N \times(I-N)^{-1}
$$

(5) For each row and column, the sum is calculated. The results $\left(R_{i}\right)$ and $\left(D_{j}\right)$ represent the direct and indirect effect of each component $(i, j)$ on overall knowledge management drivers.

$$
\begin{array}{ll}
R_{i}=\sum_{j=1}^{n} t_{i j} & ; \forall i \\
D_{j}=\sum_{i=1}^{n} t_{i j} & ; \forall i
\end{array}
$$

(6) The net effect $\left(E_{i}\right)$ and the overall prominence $\left(P_{i}\right)$ is calculated from the following expressions.

$$
\begin{aligned}
& P_{i}=\left\{R_{i}+D_{j} \mid i=j\right\} \\
& E_{i}=\left\{R_{i}-D_{j} \mid i=j\right\}
\end{aligned}
$$

The maximum value of $\left(P_{i}\right)$ determines the highest impact of the corresponding criteria on overall relationships. The positive or negative $\left(E_{i}\right)$ value shows the cause or reliable nature of the criterion on the decision-making matrix (Tzeng, Chiang, and Li, 2007). 
In this research, grey DEMATEL has been employed to analyse the relationship between different knowledge management drivers from three perspectives, the academics, the business managers, and the aggregated opinion of both parties. By applying this method, the cause and effect drivers and their relationships are extracted and illustrated.

\section{DANP}

Over the past decades, scholars have implemented multicriteria decision-making (Hereforth MCDM) approaches on various managerial problems (Yang and Tzeng, 2011). A group of MCDM approaches, such as Analytical Network Process (ANP) or DEMATEL-ANP (DANP), mainly focus on assessing the criterion rank based on the expert opinion. Unlike classical statistical factor analysis, the main advantage of these methods is their focus on the interdependent relationship between criteria in cases (Chen and Lin, 2018). Although the ANP method developed by (Hsu, Wang, and Tzeng (2012) overcame the classic AHP, this method assumes equal weights for the criterion. Therefore, (Tzeng et al., 2007) proposed DANP to combine the ANP and DEMATEL models into a single structure.

A study by (Chen and Lin, 2018) is employed to illustrate the DANP process steps:

(1) Normalised $C^{H}$ matrix is obtained by dividing every row in $G_{i j}$ by the sum of the row $\left(S_{i}\right)$.

$$
C^{H}=\left[\begin{array}{ccc}
G_{11} & \ldots & G_{1 m} \\
G_{i 1} & \ldots & G_{1 m} \\
G_{m 1} & \ldots & G_{m m}
\end{array}\right] \begin{gathered}
S_{1} \\
S_{m}
\end{gathered}
$$

Where $S_{i}=\sum_{j=m}^{1} G_{i j}$

(2) To obtain the unweighted supermatrix, the $C^{H}$ is transposed as below.

$$
F^{m}=\left(C^{H}\right)^{\prime}=\left[\begin{array}{lll}
H_{11} & \ldots & H_{1 m} \\
H_{i 1} & \ldots & H_{1 m} \\
H_{m 1} & \ldots & H_{m m}
\end{array}\right]
$$

(3) In this step, if a matrix consists of categories and subcategories, the weighted supermatrix is calculated and then the influence of each factor is summarised. However, in the following research, several knowledge transportation factors are evaluated. Therefore, by limiting the supermatrix, the overall priority is calculated as below. 


$$
W^{\text {limit }}=\lim _{k \rightarrow \infty}\left(C^{H^{\prime}}\right)^{k}
$$

The obtained results from the $W^{\text {limit }}$ produces the DANP influential weights. These weights are sorted to achieve the rank of each factor in this investigation.

\section{Case study application}

As mentioned earlier, the evaluation of the knowledge drivers encompasses two phases. In the first stage, five academic members were asked to fill the questionnaire. Simultaneously, the business experts introduced earlier in Table 1 were asked to give their opinion about the influence of each knowledge driver based on their industry. According to Table 3, the average of the collected questionaries answers was converted to numerical grey values. The business professionals' results as a sample are proposed below.

Please insert Table 3 here.

Using (16), the delta value is computed, and the normalised matrix is assembled, as shown in Table 4. Note that the presence of "strongly effective" in columns result in the normalised matrix be the same as the initial pairwise matrix. Therefore, according to (17), normalised crisp values are obtained as below. According to (17) the matrix is then normalized and then, at the final step

of converting grey numbers to crisp values, $Z_{i j}^{p}$ for each cell is calculated. As discussed previously in (20), (21), and (22), the total relation matrix should be defined. As a result, the sum of each row is computed, and the maximum value is determined. The normalised matrix is then subtracted from a unit matrix. The total relation matrix is computed in Table 4 according to (22).

Please insert Table 4 here.

The $\left(\mathrm{R}_{\mathrm{i}}\right)$ and $\left(\mathrm{D}_{\mathrm{j}}\right)$ values in Table 7 are used to determine each criterion's strength and impact range. Following that, the overall prominence (23) and net effect (24) equations are computed. As shown in Table 5, the maximum value for overall prominence indicates the most influential factor 
relative to the other drivers. Similarly, positive net effect values indicate that these factors affect the entire matrix. In contrast, a negative value indicates that other variables influence the factor.

Please insert Table 5 here.

The results obtained in the total relation matrix are set in the DANP approach to sort the drivers in each category. By transposing the matrix and repeating step (12) three times, the results are achieved in Table 6.

Please insert Table 6 here.

At the last step of the G-DEMATEL, the results are plotted shown in Table 7. Moreover, using an open-source application developed by (Napoles et al. 2018), the prominence-causal DEMATEL relationship chart with an equal weight of 0.5 for all components is illustrated in Table 7.

Please insert Table 7 here.

Regarding the business expert profiles presented in Table 1, the COCOSO approach is implemented to evaluate various industry types' driver ranks. The aim is to address the function of the results on different business models. The knowledge drivers chart shows that knowledge availability is the most popular criterion among business and academic experts. Whereas taking the risk of absorbing knowledge is given the least attention. Although academic members prefer absorbing knowledge with full reliance on their background knowledge and experience, the manufacturers favour taking advantage of information with the least complexity and in the best structure. In other words, academic members should evaluate new knowledge and transform it into a more simplified structure and then present it to the industry. This framework decreases the risk of abortive information injection in companies. 
The weight of the decision-making matrix is taken from the results obtained in the DANP ranking, acknowledging that $\sum W_{i}=1$. The rows value for each expert is achieved by repeating the G-DEMATEL and DANP five times in each case. Thus, the following Table 8 is obtained:

Please insert Table 8 here.

The normalised matrix is calculated by computing each column's maximum and minimum values and subtracting them from one another. The normalised matrix is then obtained following equations (2) and (3). Following that, the matrix is multiplied by the weight values, and by assessing the weighted comparability sequence (S) and the whole of the power weight of comparability sequences (P), the values of $k_{a}, k_{b}, k_{c}$ are achieved as shown in Table.9.

Please insert Table 9 here.

Accordingly, the experts' opinions rank is given in Table 10, combining Table 9 where the ranks of each driver are earlier indicated for business experts and the findings of COCOSO, it is clear that as the organisational rank levels up, the executives give less attention to the knowledge availability, motivation in learning, or the learning framework. However, from a marketing manager's point of view, as an instance, with a closer relationship with employees, the availability of simplified knowledge is a priority. The least risk and certainty in absorbing new information is the priority for high-level managers. On the contrary, those in the lower organisational chart prefer less complex with easy-to-learned systems and structures. The social tie between personnel is a prime concern for high-ranked managers, and both groups have the same concern regarding how well they can trust the new information.

Please insert Table 10 here.

From the business type viewpoint, manufacturers prefer absorbing low-cost knowledge with a high transfer pace. However, in a service-type business, the quality and the bond between 
employees is the priority. This group tends to take the least risk and learn the upcoming information based on their organisation (i.e., culture, experience). On the other hand, manufacturers are highly interested in resolving ambiguity and complexity in finding new technology.

\section{Theoretical and managerial contributions}

Numerous inter-organizational arrangements have evolved over the last several decades due to the increasing importance of services, the growing volume of information, an increasingly educated and trained workforce, technological advancements, an increasingly virtual work environment, and advances in artificial intelligence and automation. The common denominator among those arrangements has been their knowledge-driven nature, which has been fueled by the increased value of knowledge as capital and the primary factor of production. Knowledge is the industrial economy's equivalent of financial and physical capital and the agricultural economy's equivalent of land and physical labour. As such, its generation through interaction, practise, and experimentation and its sharing and reuse for improved management strategies and operations are critical processes in inter-organizational arrangements. By elucidating key factors influencing those processes from the perspectives of scholars and practitioners, we have derived some lessons for both theory and management practice.

Our research makes two theoretical contributions: first, it identifies a set of factors that contribute to the success of knowledge management strategies in both national and international interorganizational settings. Second, this study used an innovative method to validate these factors and their interrelationships by surveying academics and practitioners in knowledge management and international business. The identification of critical success factors for knowledge management in inter-organizational arrangements adds to the body of research in fields such as international business engagement and inter-organizational knowledge management, which have significant implications for areas such as organizational learning (Iebra Aizpura et al., 2011), business culture (Chen et al., 2016), and amenity management. Additionally, the classification of these factors and visualization of their relationships opens up new avenues for research in the knowledge management domain, as they apply not only to inter-and international settings but also intraorganizational settings, as they encompass elements such as organizational culture, knowledge 
management tools, and the exploration and exploitation of knowledge. The synthesis of academic and practitioner perspectives on critical success factors for knowledge management strategies and operations lays the groundwork for future research.

From a methodological standpoint, three quantitative steps were taken in this research to determine the most critical knowledge transformation drivers from a donor to a recipient. The combination of G-DEMATEL and DANP, used previously in scientific publications, results in the relationship between drivers. Additionally, it depicted the ranking of factors based on the consensus of experts. The novel aspect of this study is the incorporation of a newly developed MCDM approach (COCOSO) with previously obtained results. The authors used the business DANP weights to evaluate businesses from a clustering perspective. The scholars demonstrated the impact of drivers on various business types using a novel G-DEMATEL-DANP-COCOSO approach.

Our research contributes to increasing awareness of the critical role of absorption capacity in interorganizational arrangements. Having access to a shared set of drivers enhances management's ability to locate pertinent knowledge within and outside collaborative firms and appreciate its significance for their business strategy and operations (Ciborra and Andreu, 2001). This enhanced comprehension enables them to appreciate the value of new information and knowledge, assimilate it, and apply it to commercial ends (Cohen and Levinthal,1990). Second, this research contributes to a better understanding of the interrelationships between the key drivers of knowledge management, enabling management to develop more effective strategies for addressing firmspecific cultural differences. Collaborations between organizations are dynamic social systems that evolve as a result of repeated interactions between organization members (Wankhade and Patnaik, 2019). While firms that pursue a cooperative strategy and form an alliance may share knowledge management policies and procedures, their perceptions of the drivers of such management practices - particularly cultural issues - are frequently divergent. Understanding the effects of cultural differences, behaviours, and attitudes across organizations enables cooperative organizations to develop critical capabilities and competencies to design solutions that fit their internal and external environments.

Our third significant contribution to management practise is an appreciation for the critical nature of the systems and structures that define the nature of collaboration in inter-organizational settings, 
as well as the risks associated with them. Inter-organizational partnerships and collaborative efforts rely on systems and structures that facilitate communication and contribute to developing an internal culture that values and promotes collaboration and knowledge sharing as a critical operating principle (DeHoog, 2015). As mentioned previously in the introduction section, academic members and business managers should demonstrate their perspectives on the most practical knowledge transfer drivers in light of the industrial era's significant changes and the rise of academic members collaborating in industry. The literature review resulted in the dissemination of ten piths of knowledge. This means that businesses and academics already share a common belief in the importance of investing in each factor, regardless of its practical significance. While acknowledging several limitations of our research, such as the inability to conduct in-depth interviews with business owners due to pandemic safety regulations, The remainder of this section proposes a more advanced and practical driver evaluation based on the opinions of our admirable interviewees who volunteered their time for this research.

Many pieces of research, such as (Ho et al., 2019), have hypothesized that an imprecise understanding of knowledge sharing, for example, could be a factor in foreign partner knowledge acquisition failure $\left(\mathrm{D}_{4}\right)$. Additionally, with the emergence of definitions such as open innovation, businesses have allocated a sizable portion of their budget to RandD projects with third-party vendors. This issue has compelled organizations to develop trust contracts between parties that have infiltrated the annual budgets of international organizations in recent years $\left(\mathrm{D}_{10}\right)$. However, the unanswered question is how each category is prioritized concerning its functionality in the knowledge-sharing process. In our interviews with manufacturers, the ambiguity of transferred knowledge from Chinese and Russian companies, for example, and a lack of trust between parties were the primary source of concern, whereas service-oriented business owners were more concerned with the knowledge clearance provided by such countries. Academic members expressed a shared concern about the importance of external knowledge acquisition capability. A critical factor is the availability of knowledge and trust between parties inside and outside an international company.

From a Pareto optimization standpoint, our goal is to minimize budget waste and encourage businesses to develop a sustainable knowledge-sharing mechanism over time. According to an 
academic group interview, businesses should focus on the most significant causing factors, with the remainder expected to be obtained due to proper implementation of the major causing factors. Thus, based on our findings, both academic and business volunteers agreed that factors $\mathrm{D}_{10}$ or $\mathrm{D}_{4}$ should be highlighted, for example, in exercise. However, the results are inconsistent. According to academic attitudes, four items $\left(\mathrm{D}_{5}, \mathrm{D}_{6}, \mathrm{D}_{7}\right.$, and $\left.\mathrm{D}_{9}\right)$ are causal factors, while the remaining items are emerging effects of these practices. As a result, the managers identified six factors $\left(D_{1}, D_{2}, D_{3}\right.$, $\left.D_{6}, D_{8}, D_{9}\right)$ as the underlying causes of knowledge sharing in organizations. Finally, based on a mixed assessment of these factors, five causing factors $\left(\mathrm{D}_{2}, \mathrm{D}_{3}, \mathrm{D}_{5}, \mathrm{D}_{6}, \mathrm{D}_{9}\right)$ were identified as the most critical categories on which businesses should concentrate their efforts. As illustrated in Table.6 and the preceding factors, the DANP results indicate trust is the most rewarding criterion for both groups' ideas. This issue has received less attention in the literature, and both scholars and managers must consider mechanisms for establishing trust within and between parties involved in knowledge sharing.

Meanwhile, the ninth criterion, risk of knowledge sharing, is the most negligible weighted factor in managers' and academic members' decision-making. As a result, because the risk of acquiring knowledge may result in the firm's wealth being wasted, managers should consider risk as a critical component of knowledge sharing. One of the primary concerns of manufacturers was their experts' reluctance to absorb knowledge for various reasons. Concerns about job loss, authority loss, and feeling belittled were the primary reasons experts resisted sharing knowledge $\left(\mathrm{D}_{3}\right)$. When the combined attitudes scores were analyzed, $\left(\mathrm{D}_{3}\right)$ emerged as the most influential factor in enabling knowledge sharing across organizations. As a result, academic members should foster a culture of information sharing in universities. Meanwhile, managers should train their employees to accept new information and share knowledge within their firms, as this threatens their position and improves their knowledge. Because service-oriented managers and overall attitudes toward the services and mechanisms that enable effective knowledge sharing are highly ranked, and $\left(D_{7}\right)$ is demonstrated to be a causal factor, managers are expected to utilize these factors.

Nowadays, as big data and performance KPIs become more prevalent in organizations, managers must evaluate their investments in causing drivers to determine how well their firm has been able to achieve the effect factors. It is recommended that business intelligence departments develop 
specific performance indicators to assess the functionality of the suggested drivers that are expected to facilitate knowledge sharing across the organization. Finally, it is worth emphasizing that the novelty of this research does not stem from the creation of a novel mathematical framework. Because this issue has not been approached from a dual perspective in which academics and business owners share their perspectives on knowledge sharing drivers, we believe that the remarkable effect of this research at the initial stage will assist business owners in

prioritizing and allocating budget more purposefully. Our objective is to increase awareness of the factors that influence knowledge transfer to facilitate significant strategic planning in organizations that are evolving knowledge sharing at a faster pace. We hope that these findings serve as a valuable guide for scholars interested in contributing more meticulously to the function of knowledge sharing in organizations.

\section{Conclusion}

Literature has investigated inter-organisational arrangements from different perspectives. This paper explores key drivers of successful knowledge management practices in inter-organisational settings. As such, the influential factors were identified through extensive literature review, which combined with the views of experts from academia and industry (international firms). In this vein, an innovative multi-criteria decision-making approach, using COCOSO-G-DEMATEL, and DANP, has been employed to present the cause-effect relationships among the drivers of knowledge management in inter-organisational arrangements. Consequently, the ranking of factors based on the experts' overall opinion was used to discuss theoretical and managerial contributions.

Although a grey environment has been chosen to evaluate the DEMATEL approach in an academic and business environment with two types of manufacturing and service industry types, it is first suggested to broaden this research with a focus on other business types for a more comprehensive evaluation of the impact of these factors on inter-organisational information transfer. Secondly, this research is subjected to be extended by moving into a more complex uncertain environment utilising the standard fuzzy sets, interval-valued fuzzy sets (IVFs), interval value intuitionistic fuzzy sets (IVIFs), or hesitant fuzzy sets (HFs). Moreover, these factors are 
candid evaluations using the BOCR (benefit, opportunity, cost, and risk) methodology to show other knowledge management drivers' social, economic, or technological perspectives. 


\section{References}

Agostini, L., Nosella, A., Sarala, R., Spender, J.C., and Wegner, D. (2020), “Tracing the evolution of the literature on knowledge management in inter-organizational contexts: a bibliometric analysis", Journal of Knowledge Management, 24(2), pp. 463-490.

Akram, T., Lei, S., Haider, M.J., and Hussain, S.T. (2020), "The impact of organizational justice on employee innovative work behavior: Mediating role of knowledge sharing", Journal of Innovation and Knowledge.

Alimadadi, S., Bengtson, A., and Salmi, A. (2019), "Disruption, dissolution and reconstruction: A dialectical view on inter-organizational relationship development", Scandinavian Journal of Management, 35(3), p. 101047.

Anjaria, K. (2020), "Negation and Entropy: Effectual Knowledge Management Equipment for Learning Organizations", Expert Systems with Applications, p. 113497.

Balland, P.A., Boschma, R., Crespo, J., and Rigby, D.L. (2019), "Smart specialization policy in the European Union: relatedness, knowledge complexity and regional diversification. Regional Studies, 53(9), pp. 12521268.

Bhatti, S.H., Zakariya, R., Vrontis, D., Santoro, G., and Christofi, M. (2020), "High-performance work systems, innovation and knowledge sharing: An empirical analysis in the context of project-based organizations", Employee Relations, 43(2), pp. 438-458.

Björkman, I., Stahl, G.K., and Vaara, E. (2007), "Cultural differences and capability transfer in cross-border acquisitions: The mediating roles of capability complementarity, absorptive capacity, and social integration", Journal of International Business Studies, 38(4), pp. 658-672.

Canzaniello, A., Hartmann, E., and Fifka, M.S. (2017), "Intra-industry strategic alliances for managing sustainability-related supplier risks: Motivation and outcome", International Journal of Physical Distribution and Logistics Management, 47(5), pp. 387-409.

Cavusgil, T.S., and Knight, G. (2015), "The born global firm: An entrepreneurial and capabilities perspective on early and rapid internationalization", Journal of International Business Studies, 46(1), pp. 3-16.

Chen, S.H., and Lin, W.T. (2018), "Analyzing determinants for promoting emerging technology through intermediaries by using a DANP-based MCDA framework", Technological Forecasting and Social Change, 131, pp. 94-110.

Chen, Y.H., Lin, T.P., and Yen, D.C. (2014), "How to facilitate inter-organizational knowledge sharing: The impact of trust", Information and Management, 51(5), pp. 568-578.

Chen, J., Tong, L., and Ngai, E.W.T. (2007), "Inter-organizational knowledge management in complex products and systems", Journal of Technology Management in China, 2(2), pp. 134-144.

Chen, P.L., Tan, D., and Jean "Bryan," R.J. (2016), "Foreign knowledge acquisition through inter-firm collaboration and recruitment: Implications for domestic growth of emerging market firms", International Business Review, 25(1), pp. 221-232.

Cheng, J.H. (2011), "Inter-organizational relationships and information sharing in supply chains", International Journal of Information Management, 31(4), pp. 374-384.

Cheng, J.H. (2011), "Inter-organizational relationships and knowledge sharing in green supply chains-Moderating by relational benefits and guanxi”, Transportation Research Part E: Logistics and Transportation Review, 47(6), pp. 837-849.

Cheng, J.H., and Fu, Y.C. (2013), "Inter-organizational relationships and knowledge sharing through the relationship and institutional orientations in supply chains", International Journal of Information Management, 33(3), pp. 473-484.

Cheng, J.H., Chen, S.W., and Chen, F.Y. (2013), "Exploring how inter-organizational relational benefits affect information sharing in supply chains. Information Technology and Management, 14, pp. 283-294.

Crupi, A., Del Sarto, N., Di Minin, A., Phaal, R., and Piccaluga, A. (2020), "Open innovation environments as knowledge sharing enablers: the case of strategic technology and innovative management consortium", Journal of Knowledge Management, 25(5), pp. 1263-1286.

Chumg, H.F., Seaton, J., Cooke, L., and Ding, W.Y. (2016), "Factors affecting employees' knowledge-sharing behaviour in the virtual organisation from the perspectives of well-being and organisational behaviour", Computers in Human Behavior, 64, pp. 432-448.

Ciborra CU and Andreu R (2001), "Sharing knowledge across boundaries", Journal of Information Technology, 16 , pp. 73-81.

Cohen, W.M., and Levinthal, D.A. (1990), “Absorptive capacity: A new perspective on learning and innovation", Administrative Science Quarterly, pp. 128-152.

Cricelli, L., and Grimaldi, M. (2010), "Knowledge-based inter-organizational collaborations", Journal of Knowledge Management, 14, pp. 348-358. 
Curado, C., and Vieira, S. (2019), "Trust, knowledge sharing and organizational commitment in SMEs", Personnel Review, 48(6), pp. 1449-1468.

de Lima, A. (2011), "Inter-organizational relationships and knowledge sharing in green supply chains-Moderating by relational benefits and guanxi", Inter-organizational relationships and knowledge sharing in green supply chains-Moderating by relational benefits and guanxi, 47, pp. 837-849.

DeHoog, R.H. (2015), "Collaborations and partnerships across sectors: Preparing the next generation for governance", Journal of Public Affairs Education, 21(3), pp. 401-416.

Del Giudice, M., Carayannis, E.G., and Maggioni, V. (2017), "Global knowledge intensive enterprises and international technology transfer: emerging perspectives from a quadruple helix environment", The Journal of Technology Transfer, 42(2), pp. 229-235.

Deng J. (1989), “Introduction to grey system”, Journal of Grey System, 1(1), pp. 1-24.

Díaz-Reza, J.R., García-Alcaraz, J.L., Avelar-Sosa, L., and Mendoza-Fong, J.R. (2020), “The role of employees' performance and external knowledge transfer on the supply chain flexibility", In Intelligent Systems Reference Library (Vol. 166, pp. 25-51), “

Duodu, B., and Rowlinson, S. (2019), "The effect of social capital on exploratory and exploitative innovation: Modelling the mediating role of absorptive capability", European Journal of Innovation Management, 23(4), pp. 649-674.

Easterby-Smith, M., and Lyles, M. A. (2011), "Inter-Organizational Knowledge Transfer: Current Themes and Future Prospects", Journal of Management Inquiry, 45(4), pp. 677-690

Easterby-Smith, M., Lyles, M.A., and Tsang, E. W.K.K. (2008), "Inter-organizational knowledge transfer: Current themes and future prospects", Journal of Management Studies, 45(4), pp. 677-690.

Ecer, F., and Pamucar, D. (2020), "Sustainable supplier selection: A novel integrated fuzzy best worst method (FBWM) and fuzzy CoCoSo with Bonferroni (CoCoSo'B) multi-criteria model”, Journal of Cleaner Production, 266, p. 121981.

Fang, S.C., Yang, C.W., and Hsu, W.Y. (2013), "Inter-organizational knowledge transfer: The perspective of knowledge governance”, Journal of Knowledge Management, 17(6), pp. 943-957.

Flöthmann, C., Hoberg, K., and Gammelgaard, B. (2018), "Disentangling supply chain management competencies and their impact on performance: A knowledge-based view", International Journal of Physical Distribution and Logistics Management, 48, pp. 630-655.

Fu, X., Zhu, Q., and Sarkis, J. (2012), “Evaluating green supplier development programs at a telecommunications systems provider", International Journal of Production Economics, 140(1), pp. 357-367.

Gabus, A., and Fontela, E. (1973), "Perceptions of the World Problematique: Communication Procedure, Communicating with those Bearing Collective Responsibility. DEMATEL Report No. 1. Tech. rep., Battelle Geneva Research Centre, Geneva.

Garousi Mokhtarzadeh, N., Amoozad Mahdiraji, H., Jafari-Sadeghi, V., Soltani, A., and Abbasi Kamardi, A. (2020), “A product-technology portfolio alignment approach for food industry: A multi-criteria decision making with z-numbers", British Food Journal, 122(12), pp. 3947-3967.

Gil-Garcia, J.R., Guler, A., Pardo, T.A., and Burke, G.B. (2019), "Characterizing the importance of clarity of roles and responsibilities in government inter-organizational collaboration and information sharing initiatives", Government Information Quarterly, 36(4), p. 101393

Hayter, C.S., and Link, A.N. (2020), "Governance mechanisms enabling inter-organizational adaptation: Lessons from grand challenge RandD programs", Science and Public Policy, 47(2), pp. 271-282.

Ho, M.H.W., Ghauri, P.N., and Kafouros, M. (2019), "Knowledge Acquisition in International Strategic Alliances: The Role of Knowledge Ambiguity", Management International Review, 59(3), pp. 439-463.

Ho, M.H.W., Ghauri, P.N., and Larimo, J.A. (2018), "Institutional distance and knowledge acquisition in international buyer-supplier relationships: The moderating role of trust", Asia Pacific Journal of Management, 35(2), pp. 427-447.

Ho, L.A., Kuo, T.H., and Lin, B. (2012), "How social identification and trust influence organizational online knowledge sharing", Internet Research, 22, pp. 4-28.

Hsu, C.H., Wang, F.K., and Tzeng, G.H. (2012), “The best vendor selection for conducting the recycled material based on a hybrid MCDM model combining DANP with VIKOR", Resources, Conservation and Recycling, 66, pp. 95-111.

Iebra Aizpurúa, L., Zegarra Saldaña, P.E., and Zegarra Saldaña, A. (2011), "Learning for sharing: An empirical analysis of organizational learning and knowledge sharing”, International Entrepreneurship and Management Journal, 7, pp. 509-518.

Jafari-Sadeghi, V., Dutta, D. K., Ferraris, A., and Del Giudice, M. (2020), “Internationalisation business processes 
in an under-supported policy contexts: evidence from Italian SMEs”, Business Process Management Journal, 26(5), pp. 1055-1074.

Jafari Sadeghi, V., Jashnsaz, A., and Honari Chobar, M. (2014), “Organization's Conformity Assessment with Peter Senge's Learning Organization Principles in Municipality of Saveh: A Case Study", Journal of Business and Management, 16(5), pp. -58.

Jafari Sadeghi, V., Nkongolo-Bakenda, J.M., Anderson, R.B., and Dana, L.P. (2019), “An institution-based view of international entrepreneurship: A comparison of context-based and universal determinants in developing and economically advanced countries", International Business Review, 28(6), p. 101588.

Jensen, P.D.Ø. (2009), "A learning perspective on the offshoring of advanced services", Journal of International Management, 15(2), pp. 181-193.

Kim, S., and Anand, J. (Jay), “(2018), "Knowledge complexity and the performance of inter-unit knowledge replication structures”, Strategic Management Journal, 39(7), pp. 1959-1989.

Kim, W., and Park, J. (2017), "Examining structural relationships between work engagement, organizational procedural justice, knowledge sharing, and innovative work behavior for sustainable organizations", Sustainability (Switzerland), 9(2), p. 205.

Kleiner, M.M., Nickelsburg, J., and Pilarski, A.M. (2012), "Organizational and Individual learning and forgetting”, Industrial and Labor Relations Review, 65, pp. 68-81.

Koohang, A., Paliszkiewicz, J., and Goluchowski, J. (2017), “The impact of leadership on trust, knowledge management, and organizational performance: A research model", Industrial Management and Data Systems, 117(3), pp. 521-537.

Kostopoulos, K., Papalexandris, A., Papachroni, M., and Ioannou, G. (2011), “Absorptive capacity, innovation, and financial performance", Journal of Business Research, 64(12), pp. 1335-1343.

Karamat, J., Shurong, T., Ahmad, N., Afridi, S., Khan, S., and Khan, N. (2019), "Developing Sustainable Healthcare Systems in Developing Countries: Examining the Role of Barriers, Enablers and Drivers on Knowledge Management Adoption", Sustainability (Switzerland), 11(4), p.954.

Kumaraswamy, K.S., and Chitale, C.M. (2012), "Collaborative knowledge sharing strategy to enhance organizational learning”, Journal of Management Development, 31(3), pp. 308-322.

Lachance, L., Watson, C., Blais, D., Ungar, M., Healey, G., Salaffie, M., Sundar, P., Kelly, L., and Lagace, M.C. (2019), "Strengthening child and youth programs: A look at inter-organizational mentoring strategies", Evaluation and Program Planning, 76(June).

Lewis, L., Isbell, M.G., and Koschmann, M. (2010), “Collaborative tensions: Practitioners' experiences of interorganizational relationships", Communication Monographs, 77(4), pp. 460-479.

Liao, S.H., and Hu, T.C. (2007), "Knowledge transfer and competitive advantage on environmental uncertainty: An empirical study of the Taiwan semiconductor industry", Technovation, 27(6-7), pp. 402-411.

Loon, M. (2019), "Knowledge management practice system: Theorising from an international meta-standard. Journal of Business Research, 94(November 2017), pp. 432-441.

Mahdiraji, H.A., Kazimieras Zavadskas, E., Kazeminia, A., and Abbasi Kamardi, A.A. (2019), "Marketing strategies evaluation based on big data analysis: a CLUSTERING-MCDM approach”, Economic Research-Ekonomska Istrazivanja, 32(1), pp. 2882-2892.

Mahmoudi, M., Amoozad Mahdiraji, H., Jafarnejad, A., and Safari, H. (2019), "Dynamic prioritization of equipment and critical failure modes", Kybernetes, 48(9), pp. 1913-1941.

Maleki, A., and Rosiello, A. (2019), "Does knowledge base complexity affect spatial patterns of innovation? An empirical analysis in the upstream petroleum industry", Technological Forecasting and Social Change, 143(November 2018), pp. 273-288.

Martín-de Castro, G. (2015), "Knowledge management and innovation in knowledge-based and high-tech industrial markets: The role of openness and absorptive capacity", Industrial Marketing Management, 47, pp. 143-146.

Marra, M., Ho, W., and Edwards, J.S. (2012), “Supply chain knowledge management: A literature review”, Expert systems with applications, 39(5), pp. 6103-6110.

Mat, A., and Razak, C.R. (2011), "The Influence of Organizational Learning Capability on Success of Technological Innovation (Product) Implementation with Moderating Effect of Knowledge Complexity", International Journal of Business and Social Science, 2(17), pp. 217-225.

Mazorodze, A.H., and Buckley, S. (2019), Knowledge management in knowledge-intensive organisations: Understanding its benefits, processes, infrastructure and barriers, SA Journal of Information Management, 21(1), pp. 1-6.

Minbaeva, D., Pedersen, T., Björkman, I., Fey, C.F., and Park, H.J. (2014), “MNC knowledge transfer, subsidiary absorptive capacity and HRM", Journal of International Business Studies, 45(1), pp. 38-51. 
Napoles, G., Leon, M., Grau, I., and Vanhoof, K. (2018), "Fuzzy cognitive maps tool for scenario analysis and pattern classification", Proceedings - International Conference on Tools with Artificial Intelligence, ICTAI.

Nooshinfard, F., and Nemati-Anaraki, L. (2014), "Success factors of inter-organizational knowledge sharing: A proposed framework", Electronic Library, 32(2), pp. 239-261.

Nugroho, M.A. (2018), "The effects of collaborative cultures and knowledge sharing on organizational learning. Journal of Organizational Change Management, 31, pp. 1138-1152.

Olaisen, J., and Revang, O. (2017), "The dynamics of intellectual property rights for trust, knowledge sharing and innovation in project teams", International Journal of Information Management, 37(6), pp. 583-589.

Oliva, F.L. (2014), "Knowledge management barriers, practices and maturity model”, Journal of Knowledge Management, 18(6), pp. 1053-1074.

Oliva, F.L., and Kotabe, M. (2019), "Barriers, practices, methods and knowledge management tools in startups", Journal of Knowledge Management, 23(9), pp. 1838-1856.

Ouakouak, M.L., and Ouedraogo, N. (2019), "Fostering knowledge sharing and knowledge utilization: The impact of organizational commitment and trust", Business Process Management Journal, 25, pp. 757-779.

Oyemomi, O., Liu, S., Neaga, I., Chen, H., and Nakpodia, F. (2019), "How cultural impact on knowledge sharing contributes to organizational performance: Using the fsQCA approach", Journal of Business Research.

Park, S., and Kim, E.J. (2018), "Fostering organizational learning through leadership and knowledge sharing", Journal of Knowledge Management, 22, pp. 1408-1423.

Pauluzzo, R., and Cagnina, M.R. (2019), “A passage to India: cultural distance issues in IJVs' knowledge management", Knowledge Management Research and Practice, 17(2), pp. 192-202.

Peng, X., Zhang, X., and Luo, Z. (2020), "Pythagorean fuzzy MCDM method based on CoCoSo and CRITIC with score function for 5G industry evaluation", Artificial Intelligence Review, 53(5), pp. 3813-3847.

Pérez-Salazar, M.D.R., Lasserre, A.A.A., Cedillo-Campos, M.G., and González, J.C.H. (2017), "The role of knowledge management in supply chain management: A literature review", Journal of Industrial Engineering and Management, 10(4), pp. 711-788.

Ponis, S., and Koronis, E. (2013), "Inter-organizational knowledge transfer for supply chains in crisis", Proceedings of the European Conference on Knowledge Management, ECKM, 2, pp. 569-576.

Rao, Y., Yang, M., and Yang, Y. (2018), "Knowledge Sharing, Organizational Learning and Service Innovation in Tourism", Journal of Service Science and Management, 11, pp. 510-526.

Raza, S.A., Abidi, M., Arsalan, G.M., Shairf, A., and Qureshi, M. A. (2018), "The impact of student attitude, trust, subjective norms, motivation and rewards on knowledge sharing attitudes among university students", International Journal of Knowledge and Learning, 12(4), pp. 287-304.

Ren, X., Yan, Z., Wang, Z., and He, J. (2019), "Inter-project knowledge transfer in project-based organizations: an organizational context perspective", Management Decision, 58, pp. 844-863.

Rezaei, M., Jafari-Sadeghi, V., and Bresciani, S. (2020), "What Drives the Process of Knowledge Management in a Cross-Cultural Setting: The Impact of Social Capital", European Business Review, 32(3), pp. 485-511.

Rungsithong, R., and Meyer, K.E. (2020), "Trust and knowledge sharing in context: A study of international buyer-supplier relationships in Thailand", Industrial Marketing Management, 88, pp. 112-124.

Ruoslahti, H. (2020), "Complexity in project co-creation of knowledge for innovation", Journal of Innovation and Knowledge, 5(4), pp. 228-235.

Sankowska, A., and Paliszkiewicz, J. (2016), “Dimensions of institutionalized organizational trust and firm's innovativeness", Journal of Computer Information Systems, 56(2), pp. 168-174.

Secundo, G., Toma, A., Schiuma, G., and Passiante, G. (2019), "Knowledge transfer in open innovation: A classification framework for healthcare ecosystems", Business Process Management Journal, 25(1), pp. 144-163.

Song, Z.-h. (2015), “Organizational learning, absorptive capacity, imitation and innovation”, Chinese Management Studies, 9, pp. 97-113.

Subramanian, A.M., Bo, W., and Kah-Hin, C. (2018), "The role of knowledge base homogeneity in learning from strategic alliances", Research Policy, 47(1), pp. 158-168.

Sukumar, A., Jafari-Sadeghi, V., Garcia-Perez, A., and Dutta, D. K. (2020), “The potential link between corporate innovations and corporate competitiveness: evidence from IT firms in the UK”, Journal of Knowledge Management, 24(5), pp. 965-983.

Thannhuber, M.J., Bruntsch, A., and Tseng, M.M. (2017), “Knowledge Management: Managing Organizational Intelligence and Knowledge in Autopoietic Process Management Systems - Ten Years into Industrial Application", Procedia CIRP, 63, pp. 384-389. 
Toma, A., Secundo, G., and Passiante, G. (2016), "Open Innovation and network approaches in Healthcare ecosystems", Proceedings of th 28th International Business Information Management Association Conference - Vision 2020: Innovation Management, Development Sustainability, and Competitive Economic Growth, (pp. 2431-2435).

Tzeng, G.H., Chiang, C.H., and Li, C.W. (2007), "Evaluating intertwined effects in e-learning programs: A novel hybrid MCDM model based on factor analysis and DEMATEL", Expert Systems with Applications, 32(4), pp. 1028-1044.

Vaccaro, A., Parente, R., and Veloso, F.M. (2010), "Knowledge management tools, inter-organizational relationships, innovation and firm performance", Technological Forecasting and Social Change, 77(7), pp. 1076-1089.

Wang, L., Huo, D., and Motohashi, K. (2019), “Coordination Mechanisms and Overseas Knowledge Acquisition for Chinese Suppliers: The Contingent Impact of Production Mode and Contractual Governance", Journal of International Management, 25(2), p. 100653.

Wang, W.T., and Hou, Y.P. (2015), "Motivations of employees' knowledge sharing behaviors: A selfdetermination perspective", Information and Organization, 25(1), pp. 1-26.

Wang, H., and Meng, X. (2019), "Transformation from IT-based knowledge management into BIM-supported knowledge management: A literature review”, Expert Systems with Applications, 121, pp. 170-187.

Wankhade, P. and Patnaik, S. (2019), "Collaboration and Governance in the Emergency Services: Issues, Opportunities and Challenges", Palgrave McMillan: London

Wei, Y., and Miraglia, S. (2017), "Organizational culture and knowledge transfer in project-based organizations: Theoretical insights from a Chinese construction firm", International Journal of Project Management, 35(4), pp. 571-585.

Wu, W.W., and Lee, Y.T. (2007), "Developing global managers' competencies using the fuzzy DEMATEL method", Expert Systems with Applications, 32(2), pp. 499-507.

Xie, X., Wang, L., and Zeng, S. (2018), "Inter-organizational knowledge acquisition and firms' radical innovation: A moderated mediation analysis”, Journal of Business Research, 90, pp. 295-306.

Yang, T.M., and Maxwell, T.A. (2011), "Information-sharing in public organizations: A literature review of interpersonal, intra-organizational and inter-organizational success factors", Government Information Quarterly, 28(2), pp. 164-175.

Yang, J.L., and Tzeng, G.H. (2011), “An integrated MCDM technique combined with DEMATEL for a novel cluster-weighted with ANP method”, Expert Systems with Applications, 38(3), pp. 1417-1424.

Yazdani, M., Zarate, P., Kazimieras Zavadskas, E., and Turskis, Z. (2019), “A combined compromise solution (CoCoSo) method for multi-criteria decision-making problems”, Management Decision, 57(9), pp. 2501-2519.

Zahra, S.A., and George, G. (2002), “Absorptive capacity: A review, reconceptualization, and extension. Academy of Management Review, 27(2), pp. 185-203.

Zhou, L., and Nunes, M.B. (2016), "Barriers to knowledge sharing in Chinese healthcare referral services: An emergent theoretical model", Global Health Action, 9(1), p. 29964. 


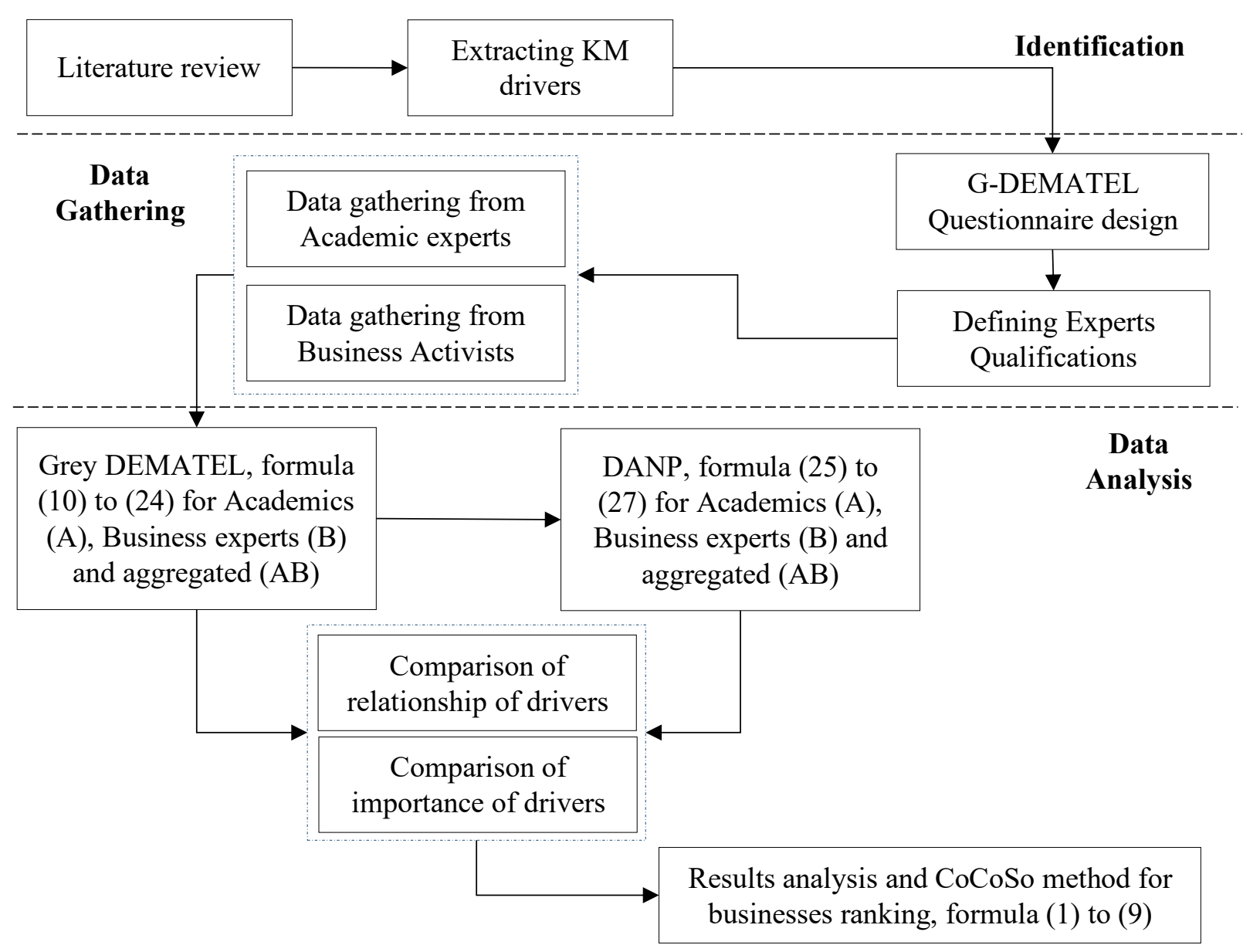

Figure 1. Research Framework 


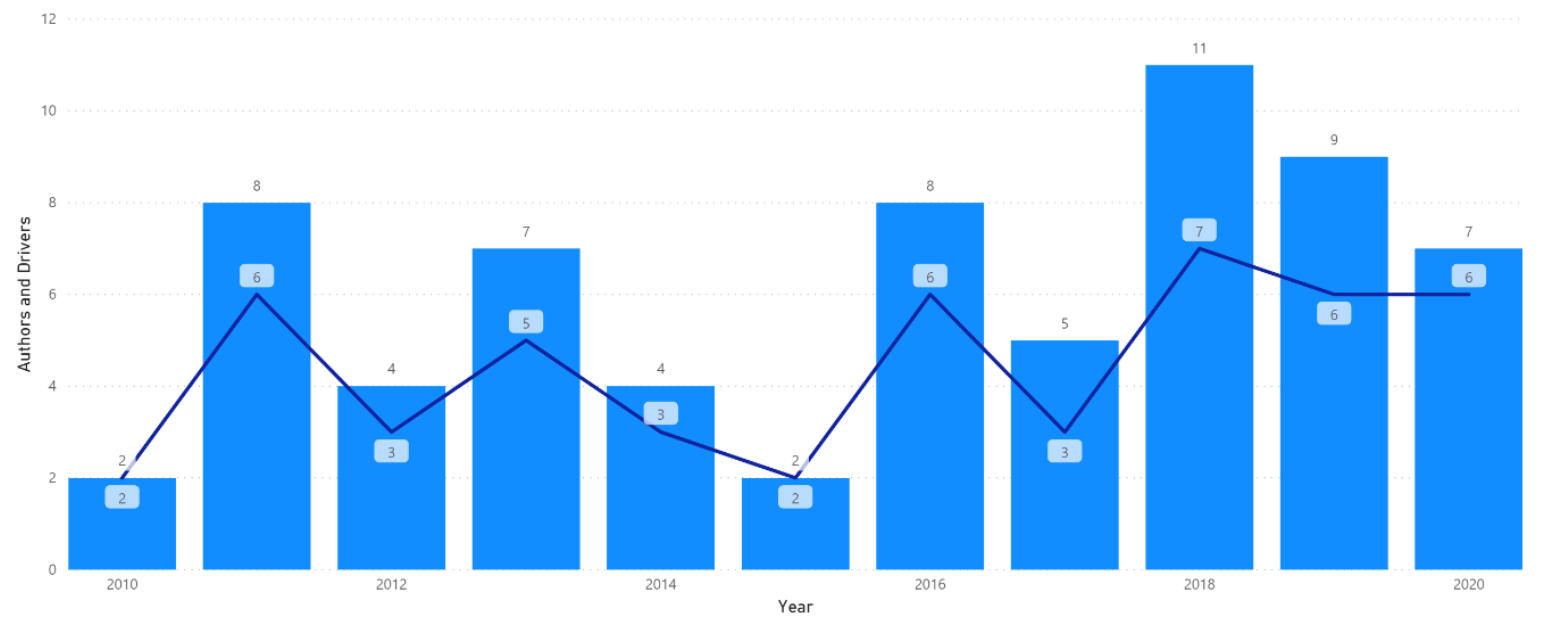

Figure 2. The distribution of knowledge sharing articles for each criterion 


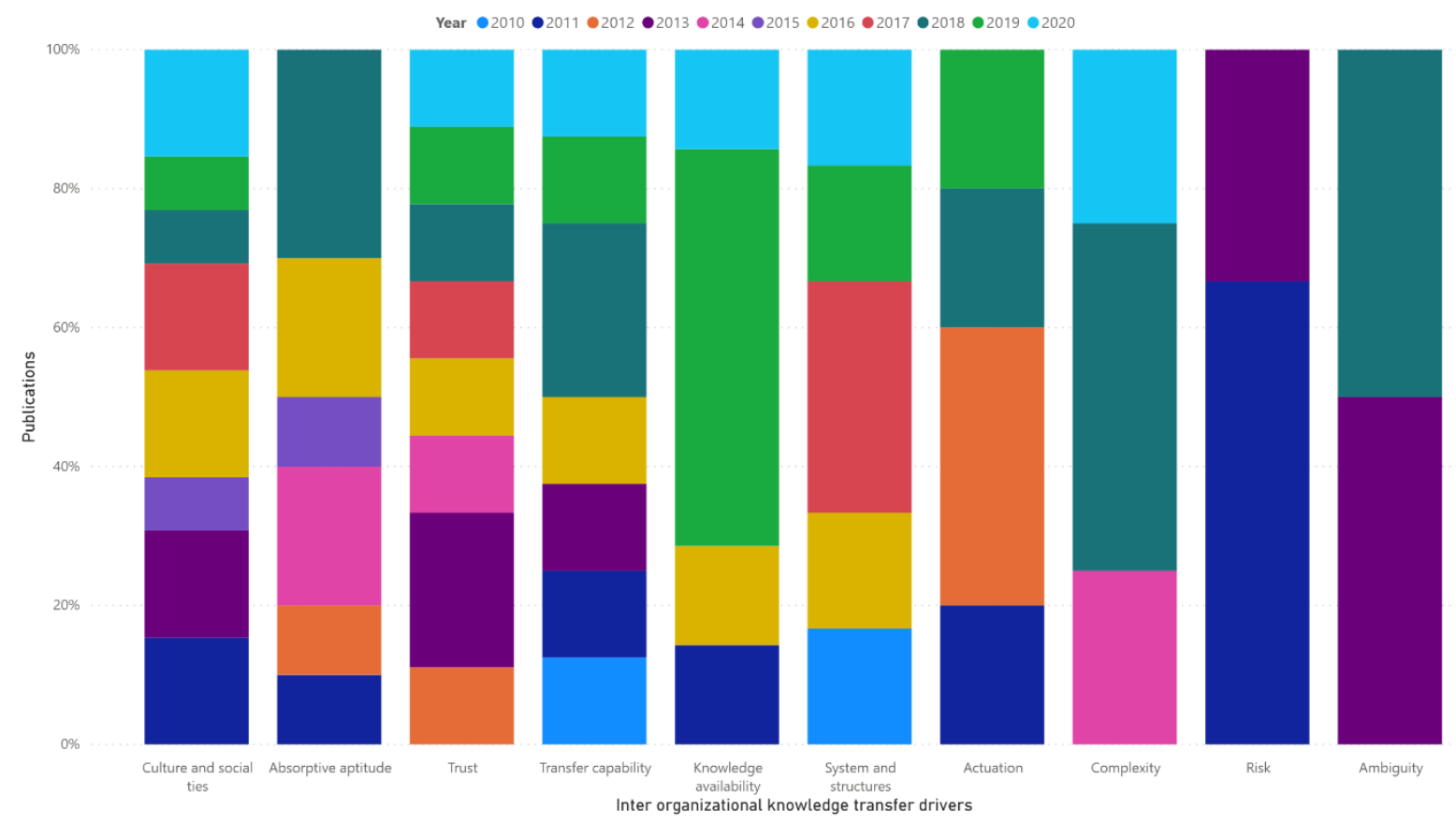

Figure 3a. The distribution of knowledge drivers per year

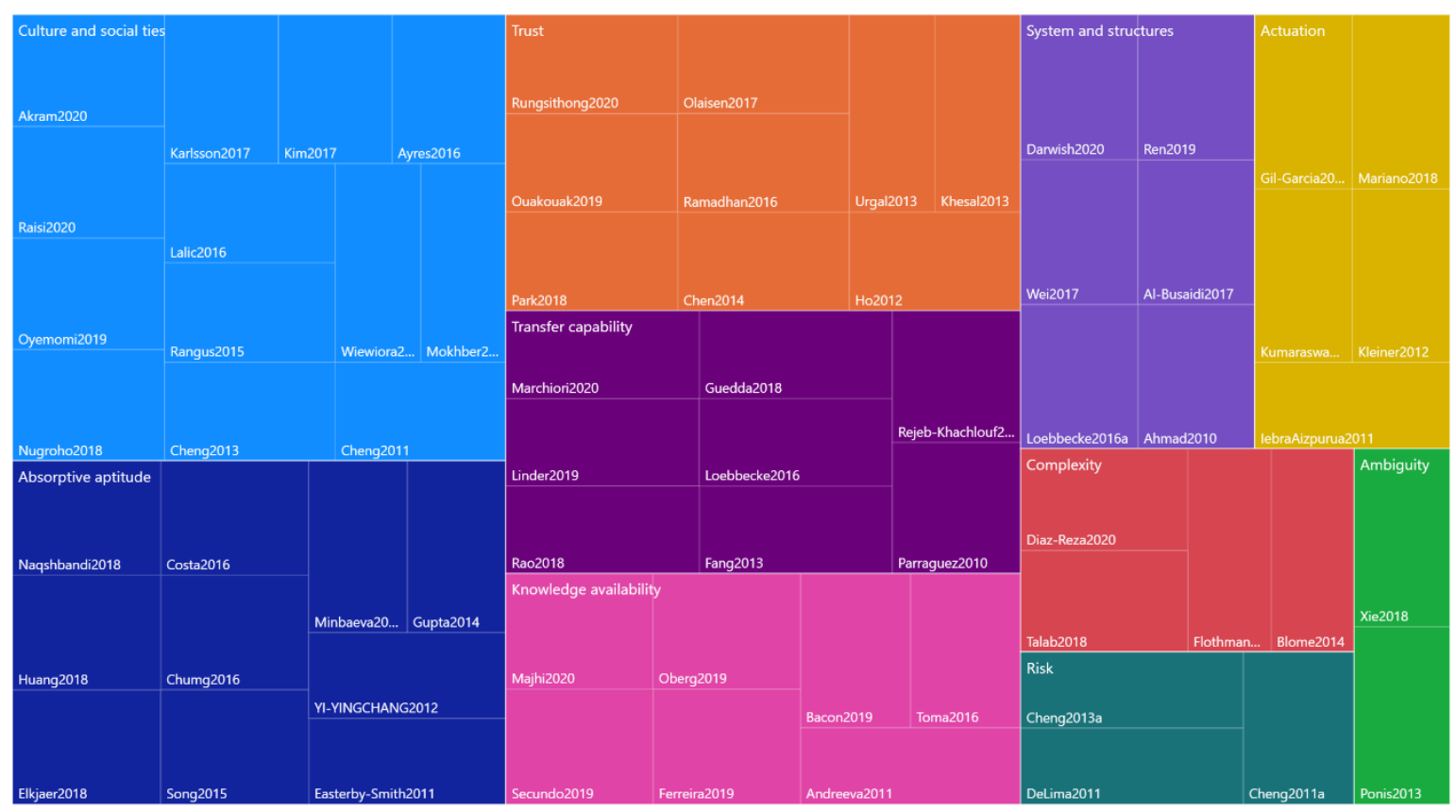

Figure $\mathbf{3}_{\mathbf{b}}$. The distribution of knowledge drivers per author 
Table 1. Business experts' profile

\begin{tabular}{ccccccc}
\hline Code & Gender & Age & $\begin{array}{c}\text { Education } \\
\text { attainment }\end{array}$ & Job position & $\begin{array}{c}\text { Working } \\
\text { experience }\end{array}$ & Industry \\
\hline 1 & $\mathrm{M}$ & $30 \mathrm{~s}$ & $\begin{array}{c}\text { Master } \\
\text { No }\end{array}$ & CEO & 4 & Online retail \\
2 & $\mathrm{~F}$ & $50 \mathrm{~s}$ & $\begin{array}{c}\text { Mniversity } \\
\text { education }\end{array}$ & $\begin{array}{c}\text { manager } \\
\text { Board member } \\
\text { and sales } \\
\text { manager }\end{array}$ & 25 & $\begin{array}{c}\text { Manufacture } \\
\text { (Ceramic/ Tales) }\end{array}$ \\
3 & $\mathrm{M}$ & $30 \mathrm{~s}$ & Master & $\begin{array}{c}\text { Bachelor } \\
\text { Sales manager }\end{array}$ & $\begin{array}{c}\text { Manufacture } \\
\text { (Truck) }\end{array}$ \\
5 & $\mathrm{M}$ & $40 \mathrm{~s}$ & Bachelor & $\begin{array}{c}\text { Director } \\
\text { general }\end{array}$ & 20 & $\begin{array}{c}\text { Manufacture } \\
\text { Service (Consultancy and } \\
\text { regulative authority) }\end{array}$ \\
\hline
\end{tabular}


Table 2. Linguistic term to Grey Value Converter (Beheshti et al, 2016)

\begin{tabular}{lc}
\hline Linguistic Term & Grey Value \\
\hline Strongly effective & {$[0.8,1]$} \\
Effective & {$[0.6,0.8]$} \\
Nearly effective & {$[0.5,0.6]$} \\
Neither effective nor ineffective & {$[0.4,0.5]$} \\
Nearly ineffective & {$[0.3,0.4]$} \\
Ineffective & {$[0.2,0.3]$} \\
Strongly ineffective & {$[0.1,0.2]$} \\
\hline
\end{tabular}


Table 3. The average of the business experts pairwise grey matrix

\begin{tabular}{llllllllllllllllllllllll}
\hline & \multicolumn{1}{c}{ D01 } & \multicolumn{1}{c}{ D02 } & \multicolumn{1}{c}{ D03 } & \multicolumn{1}{c}{ D04 } & \multicolumn{1}{c}{ D05 } & \multicolumn{1}{c}{ D06 } & \multicolumn{2}{c}{ D07 } & \multicolumn{2}{c}{ D08 } & \multicolumn{2}{c}{ D09 } & \multicolumn{2}{c}{ D10 } \\
\hline D01 & 0.0 & 0.0 & 0.5 & 0.7 & 0.6 & 0.8 & 0.4 & 0.5 & 0.3 & 0.5 & 0.7 & 0.9 & 0.7 & 0.8 & 0.4 & 0.5 & 0.6 & 0.7 & 0.6 & 0.8 \\
D02 & 0.7 & 0.8 & 0.0 & 0.0 & 0.3 & 0.4 & 0.7 & 0.8 & 0.7 & 0.9 & 0.6 & 0.7 & 0.6 & 0.7 & 0.5 & 0.6 & 0.3 & 0.4 & 0.6 & 0.7 \\
D03 & 0.7 & 0.9 & 0.6 & 0.7 & 0.0 & 0.0 & 0.4 & 0.6 & 0.5 & 0.6 & 0.6 & 0.7 & 0.6 & 0.8 & 0.6 & 0.8 & 0.4 & 0.5 & 0.6 & 0.7 \\
D04 & 0.2 & 0.3 & 0.6 & 0.8 & 0.2 & 0.3 & 0.0 & 0.0 & 0.7 & 0.8 & 0.3 & 0.4 & 0.8 & 0.9 & 0.3 & 0.5 & 0.6 & 0.7 & 0.6 & 0.8 \\
D05 & 0.3 & 0.4 & 0.6 & 0.7 & 0.3 & 0.4 & 0.7 & 0.9 & 0.0 & 0.0 & 0.4 & 0.5 & 0.7 & 0.9 & 0.5 & 0.6 & 0.6 & 0.7 & 0.7 & 0.8 \\
D06 & 0.5 & 0.6 & 0.4 & 0.6 & 0.5 & 0.7 & 0.6 & 0.8 & 0.3 & 0.4 & 0.0 & 0.0 & 0.5 & 0.6 & 0.5 & 0.7 & 0.5 & 0.7 & 0.6 & 0.8 \\
D07 & 0.3 & 0.4 & 0.4 & 0.6 & 0.2 & 0.4 & 0.6 & 0.7 & 0.6 & 0.8 & 0.3 & 0.4 & 0.0 & 0.0 & 0.4 & 0.5 & 0.3 & 0.4 & 0.7 & 0.9 \\
D08 & 0.6 & 0.8 & 0.4 & 0.5 & 0.4 & 0.5 & 0.2 & 0.3 & 0.4 & 0.5 & 0.5 & 0.6 & 0.5 & 0.7 & 0.0 & 0.0 & 0.4 & 0.5 & 0.4 & 0.5 \\
D09 & 0.3 & 0.4 & 0.2 & 0.4 & 0.2 & 0.3 & 0.7 & 0.9 & 0.7 & 0.9 & 0.4 & 0.6 & 0.5 & 0.7 & 0.5 & 0.7 & 0.0 & 0.0 & 0.7 & 0.9 \\
D10 & 0.3 & 0.4 & 0.5 & 0.6 & 0.3 & 0.5 & 0.5 & 0.6 & 0.4 & 0.6 & 0.4 & 0.5 & 0.5 & 0.6 & 0.2 & 0.3 & 0.4 & 0.5 & 0.0 & 0.0 \\
\hline
\end{tabular}


Table 4. Total relation matrix for business experts

\begin{tabular}{ccccccccccc}
\hline $\mathbf{Z}$ & D01 & D02 & D03 & D04 & D05 & D06 & D07 & D08 & D09 & D10 \\
\hline D01 & 0.66 & 0.76 & 0.66 & 0.93 & 0.95 & 0.87 & 1.07 & 0.69 & 0.71 & 1.11 \\
D02 & 0.79 & 0.69 & 0.62 & 1.00 & 1.03 & 0.85 & 1.08 & 0.72 & 0.69 & 1.12 \\
D03 & 0.79 & 0.79 & 0.57 & 0.97 & 0.99 & 0.87 & 1.08 & 0.74 & 0.70 & 1.12 \\
D04 & 0.64 & 0.72 & 0.54 & 0.78 & 0.93 & 0.73 & 0.98 & 0.62 & 0.66 & 1.02 \\
D05 & 0.68 & 0.74 & 0.57 & 0.94 & 0.84 & 0.76 & 1.04 & 0.66 & 0.69 & 1.07 \\
D06 & 0.73 & 0.74 & 0.63 & 0.96 & 0.92 & 0.72 & 1.02 & 0.70 & 0.70 & 1.09 \\
D07 & 0.59 & 0.63 & 0.49 & 0.80 & 0.84 & 0.65 & 0.77 & 0.57 & 0.56 & 0.93 \\
D08 & 0.65 & 0.62 & 0.52 & 0.75 & 0.79 & 0.70 & 0.88 & 0.51 & 0.58 & 0.88 \\
D09 & 0.67 & 0.69 & 0.56 & 0.95 & 0.97 & 0.78 & 1.01 & 0.67 & 0.60 & 1.08 \\
D10 & 0.55 & 0.58 & 0.48 & 0.74 & 0.74 & 0.63 & 0.80 & 0.51 & 0.53 & 0.74 \\
\hline
\end{tabular}


Table 5. Overall prominence and the net effect of knowledge transfer drivers

\begin{tabular}{cccccccccccc}
\hline \multicolumn{1}{c}{$\boldsymbol{P}_{\boldsymbol{i}}, \boldsymbol{E}_{\boldsymbol{i}}$} & & D01 & D02 & D03 & D04 & D05 & D06 & D07 & D08 & D09 & D10 \\
\hline \multirow{2}{*}{ Academic } & R+D & 27.75 & 27.60 & 28.41 & 25.65 & 22.19 & 28.46 & 27.76 & 29.32 & 22.09 & 29.54 \\
& R-D & -2.88 & -1.47 & -2.25 & -0.09 & 4.69 & 0.02 & 0.98 & -0.65 & 3.26 & -15.57 \\
\multirow{3}{*}{ Business } & R+D & 15.15 & 15.56 & 14.27 & 16.45 & 17.00 & 15.77 & 16.59 & 13.26 & 14.41 & 16.45 \\
& R-D & 1.68 & 1.64 & 2.97 & -1.20 & -1.02 & 0.65 & -2.90 & 0.49 & 1.56 & -10.16 \\
\multirow{2}{*}{ Mixed } & R+D & 22.57 & 22.07 & 22.11 & 22.55 & 21.14 & 22.28 & 23.11 & 21.93 & 19.69 & 23.71 \\
& R-D & -0.64 & 0.67 & 0.68 & -1.33 & 1.39 & 1.58 & -1.26 & -0.08 & 2.05 & -13.39 \\
\hline
\end{tabular}


Table 6. Knowledge drivers ranking using DANP

\begin{tabular}{ccccccc}
\hline Criteria & $\begin{array}{c}\text { Business } \\
\text { Weight }\end{array}$ & Rank & $\begin{array}{c}\text { Academic } \\
\text { Weight }\end{array}$ & Rank & $\begin{array}{c}\text { Mixed } \\
\text { Weight }\end{array}$ & Rank \\
\hline D01 & 0.086699 & 7 & 0.113886 & 3 & 0.104877 & 4 \\
D02 & 0.090328 & 6 & 0.108211 & 5 & 0.096901 & 7 \\
D03 & 0.07318 & 10 & 0.114062 & 2 & 0.097002 & 6 \\
D04 & 0.114063 & 4 & 0.095608 & 8 & 0.107823 & 3 \\
D05 & 0.116644 & 3 & 0.065204 & 10 & 0.089397 & 9 \\
D06 & 0.097371 & 5 & 0.105819 & 6 & 0.093738 & 8 \\
D07 & 0.125424 & 2 & 0.099725 & 7 & 0.110081 & 2 \\
D08 & 0.082265 & 9 & 0.111542 & 4 & 0.099425 & 5 \\
D09 & 0.08325 & 8 & 0.070099 & 9 & 0.079923 & 10 \\
D10 & 0.130777 & 1 & 0.115843 & 1 & 0.120832 & 1 \\
\hline
\end{tabular}


Table 7. Knowledge drivers rankings chart

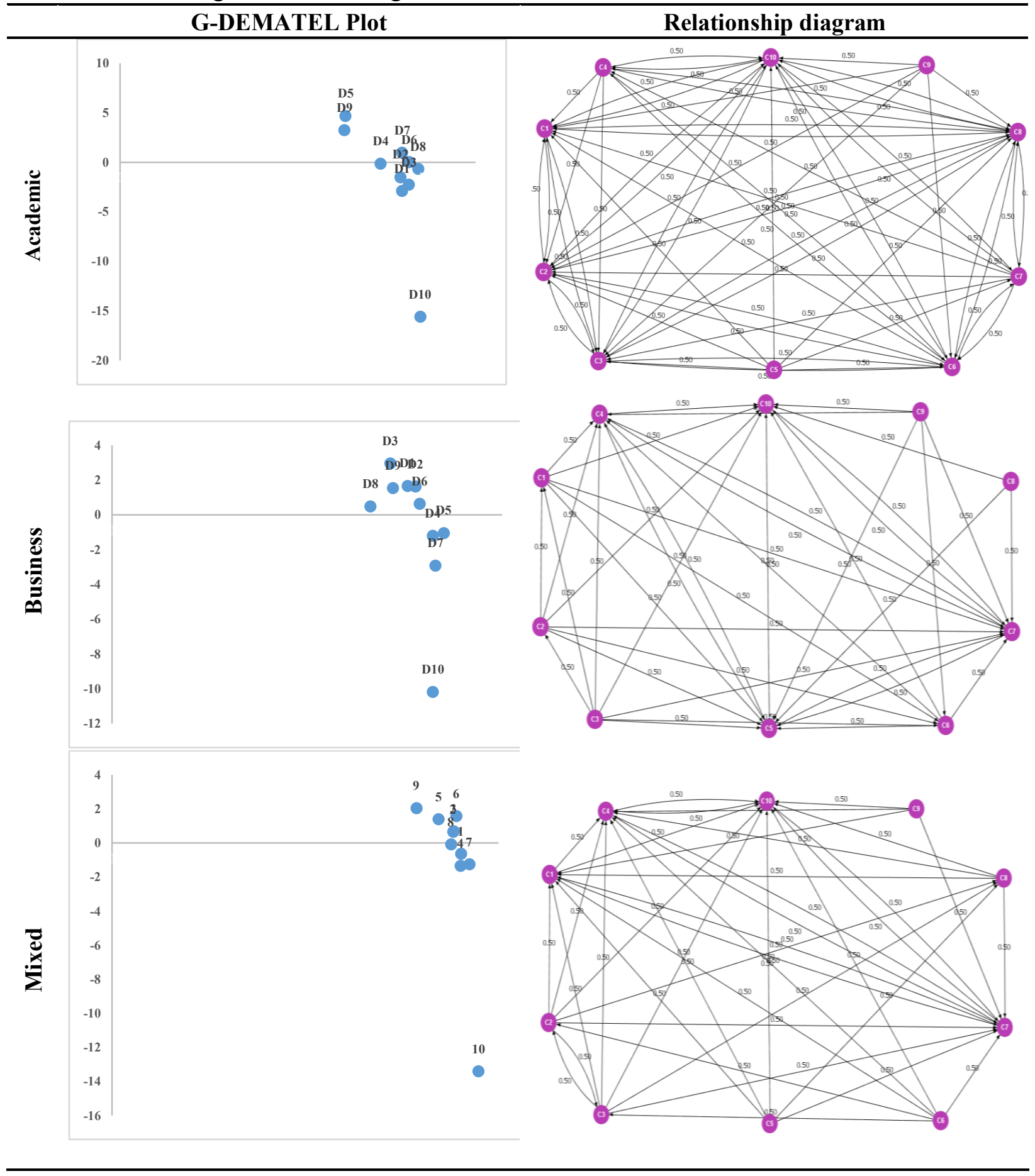


Table 8. Business decision-making matrix

\begin{tabular}{ccccccccccc}
\hline Weight & 0.09 & 0.09 & 0.07 & 0.11 & 0.12 & 0.10 & 0.13 & 0.08 & 0.08 & 0.13 \\
\hline Exp/Dri & $\mathbf{1}$ & $\mathbf{2}$ & $\mathbf{3}$ & $\mathbf{4}$ & $\mathbf{5}$ & $\mathbf{6}$ & $\mathbf{7}$ & $\mathbf{8}$ & $\mathbf{9}$ & $\mathbf{1 0}$ \\
\hline Expert 1 & 0.09 & 0.11 & 0.08 & 0.12 & 0.10 & 0.11 & 0.11 & 0.08 & 0.08 & 0.12 \\
Expert 2 & 0.09 & 0.10 & 0.07 & 0.10 & 0.12 & 0.09 & 0.11 & 0.10 & 0.08 & 0.14 \\
Expert 3 & 0.09 & 0.10 & 0.07 & 0.10 & 0.11 & 0.07 & 0.14 & 0.10 & 0.09 & 0.13 \\
Expert 4 & 0.11 & 0.04 & 0.08 & 0.13 & 0.08 & 0.13 & 0.08 & 0.11 & 0.12 & 0.11 \\
Expert 5 & 0.06 & 0.13 & 0.04 & 0.11 & 0.13 & 0.07 & 0.15 & 0.06 & 0.11 & 0.15 \\
\hline
\end{tabular}


Table 9. Weighted normalised matrix

\begin{tabular}{cccccc}
\hline Exp/Dri & $\mathbf{P}$ & $\mathbf{S}$ & $\mathbf{K}_{\mathbf{a}}$ & $\mathbf{K}_{\mathbf{b}}$ & $\mathbf{K}_{\mathbf{c}}$ \\
\hline Expert 1 & 9.310848 & 0.545126 & 0.241617 & 3.057206 & 0.968065 \\
Expert 2 & 9.532396 & 0.648713 & 0.249588 & 3.328603 & 1 \\
Expert 3 & 9.431189 & 0.622346 & 0.246461 & 3.250559 & 0.98747 \\
Expert 4 & 5 & 0.456158 & 0.133757 & 2 & 0.53591 \\
Expert 5 & 4.82051 & 0.424375 & 0.128577 & 1.894427 & 0.515159 \\
\hline
\end{tabular}


Table 10. Business experts' rank

\begin{tabular}{llc}
\hline \multicolumn{1}{c}{ Position } & \multicolumn{1}{c}{ Type } & Rank \\
\hline CEO & Service & 3 \\
Marking manager & Manufacturer & 1 \\
Sales manager & Manufacturer & 2 \\
Sales manager & Manufacturer & 4 \\
Director & Service & 5 \\
\hline
\end{tabular}

